$\int_{\mathcal{G}}^{\text {Semantics \& Pragmatics Volume 9, Article 16: 1-65, } 2016}$

\title{
Overt distributivity in algebraic event semantics*
}

\author{
Lucas Champollion \\ New York University
}

Submitted 2015-08-08 / First decision 2015-11-26 / Revision received 2016-02-02 / Accepted 2016-02-04 / Final version received 2016-02-10 / Early access 2016-06-03 / Published 2017-06-06

\begin{abstract}
This is the second in a pair of papers that aim to provide a comprehensive analysis of the semantic phenomenon of distributivity in natural language. This paper describes and explains observable cross-linguistic differences in overt distributive items in the framework of Neo-Davidsonian algebraic event semantics. The previous paper, Champollion 2016a, postulated two covert distributivity operators, D and Part, in the grammar, even though the semantic effects of D can be subsumed under the workings of Part. This paper motivates the split by arguing that distance-distributive items across languages are in essence overt versions of these operators. For example, English each lexicalizes D while German jeweils lexicalizes Part. For this reason, jeweils occurs in a wider range of distributive environments, including distribution over salient occasions. The proposed analysis explains why distributive items that can also be used as determiners, such as each and every, never allow distribution over occasions. It also accounts for the ability of these determiners to take part in cumulative readings and to interact with nondistributive event modifiers. The paper and its companion include an explicit proposal for the compositional process in event semantics.
\end{abstract}

Keywords: distance distributivity, crosslinguistic semantics, algebraic semantics, adnominal each, adverbial each, cumulative readings, quantifier float, covers

* For discussions and comments, I thank Chris Barker, Benjamin Bruening, Dylan Bumford, Seth Cable, Chris Collins, Robert Henderson, Manuel Križ, Chris LaTerza, Adam Przepiórkowski, Roger Schwarzschild, Anna Szabolcsi, Linmin Zhang, and audiences at the Stuttgart 2011 workshop on distributivity, at the 2011 Amsterdam Colloquium, at the University of Potsdam, at my 2013 and 2014 NYU seminars, and at my 2015 LSA summer institute course. For native speaker judgments, I thank Meike Baumann, Isaac Bleaman, Heather Burnett, WooJin Chung, Ivano Ciardelli, Chris Collins, Liz Coppock, Masha Esipova, Hana Filip, Daði Hafpór Helgason, Hildur Hrólfsdóttir, Gianina Iordăchioaia, Zack Jaggers, Sonia Kasyanenko, Songhee Kim, Sverrir Kristinsson, Jeremy Kuhn, Chigusa Kurumada, Luciana Meinking Guimarães, Yohei Oseki, Roumyana Pancheva, Adam Przepiórkowski, Leonor Remédio, Floris Roelofsen, Bujar Rushiti, Kjell Johan Sæbø, and Gunnar Ingi Valdimarsson. This paper builds on earlier work for which I am indebted to many people and institutions as indicated there (Champollion 2010b, 2012, 2013). I thank Todd Snider for proofreading and copyediting the paper. Special thanks to the S\&P editor, Kjell Johan Sæbø, to Malte Zimmermann, and to the reviewers.

(C)2016 Lucas Champollion

This is an open-access article distributed under the terms of a Creative Commons Attribution License (https://creativecommons.org/licenses/by/3.o/). 
Lucas Champollion

\section{Introduction}

This paper presents a compositional theory of distance distributivity that relates adnominal and adverbial distributive items, atomic and cover-based distributivity, and distributive determiners to each other. This is the second of two papers that aim to provide a comprehensive analysis of distributivity in natural language. It builds on the results obtained in its companion paper, Champollion 2016a, which focuses on covert distributivity. The papers are largely self-contained but amplify each other's results.

Overt and covert distributivity are illustrated in (1):

a. The girls each wore a black dress.

b. The girls wore a black dress.

In sentence (1a), the adverbial distributive item each distributes the predicate wear a black dress over the individual girls and leads to the entailment that each of the girls in question wears a black dress. Sentence (1b) is interpreted in the same way, even though there is no each. The ability of verb phrases to distribute in the absence of an overt distributive item has been attributed to what is traditionally called the D operator, a silent counterpart of adverbial each (Link 1987, Roberts 1987). For an overview of the major empirical phenomena related to distributivity, see also Champollion to appear: §2.

The purpose of this paper and of Champollion 2016a is to bring together several strands of research on phenomena related to the semantics and pragmatics of distributivity in natural language. One of these strands deals with overt distributivity, which is crosslinguistically often expressed via adverbials and adnominals, such as English each and German jeweils /'je:vails/. Such elements differ with respect to whether they are restricted to distribution over individuals mentioned in the same sentence, or whether they can also distribute over pragmatically salient occasions that need not have been explicitly mentioned (Moltmann 1997). This strand is motivated by the properties of adverbial each and its adnominal and determiner counterparts both in English and other languages (Zimmermann 2002b). As we will see, the meanings of these elements vary in ways that sometimes require them to distribute over atoms (individuals), such as in the case of each, and in other cases also allow them to distribute over salient nonatomic entities, such as occasions in the case of jeweils, as illustrated here: 
Overt distributivity in algebraic event semantics

(2) Hans hat jeweils zwei Affen gesehen.

Hans has DisT two monkeys seen

'Hans has seen two monkeys on each occasion.'

(German)

Another strand concerns the properties of silent distributivity operators such as the one arguably present in (1b). Covert phrasal distributivity has been at the center of a long debate as to whether it always involves distribution over atoms - singular individuals - or whether it can also involve distribution over nonatomic entities (Lasersohn 1989, Gillon 1990). This is the focus of Champollion 2016a. I reserve the term $D$ operator for distributivity operators that always distribute over atoms. As for the nonatomic version of the operator, whose meaning may be paraphrased as each salient part of, I will refer to it as the Part operator, following Schwarzschild 1996.

As this sketch already suggests, overt and covert distributivity share many similarities. In both cases, some elements can only distribute to atoms (each, D) while others can distribute to salient nonatomic entities (jeweils, Part). And as we will see, in both cases, the former elements can only distribute over pluralities that have been explicitly mentioned while the latter elements can also distribute over salient domains that have not been explicitly mentioned, such as temporal occasions. These similarities give rise to analogous questions in the overt and in the covert case. Can a given distributive item (be it a covert operator or a word) only distribute down to singular entities or also to plural entities? Do these entities need to be of a certain size or "granularity", and can this size vary from item to item? Must these entities have been overtly mentioned in the sentence and thereby contributed by semantic means, or can they also be supplied by the context via pragmatic means?

A unified semantic analysis of distributivity should make it apparent which aspects of the meanings of various distributivity operators are always the same, and along which dimensions these meanings can differ. The theory should capture the semantic variation across distributivity-related elements. The resulting system should be fully formalized and explicit.

This paper, together with Champollion 2016a, contributes towards these goals. By combining ideas from algebraic semantics and event semantics, the two papers provide a framework in which the split in overt distancedistributive items can be related to the debate in the literature on covert distributivity. In this framework, the various uses of each and similar items in other languages are all related to the distributivity operator, either in its 
semantic, atomic form as defined by Link 1987 or in its pragmatic, saliencerelated form as defined by Schwarzschild 1996. As we will see, these various uses of each and these silent operators share some part of their meanings with each other and with their counterparts across languages. This fact is captured by deriving them from related distributivity operators which differ only in possible settings of two parameters and the ranges of values they allow for them. One parameter indicates the dimension in which distributivity takes place. This can be a thematic role in some semantic instances of distributivity, or a spatial or temporal dimension in other instances. The other parameter indicates the size of the entities over which distributivity takes place, such as atoms or salient amounts of space or time. These parameters interact with each other against the background of assumptions about the metaphysics of natural language. For example, time is assumed to be either nonatomic or in any case to not make its atoms available to the semantics of natural language. As a result, when the first parameter is set to time, the second cannot be set to anything involving atoms, because time does not provide any atoms to distribute over. This idea is situated within a broader framework that connects it to aspect and measurement under the name of strata theory (Champollion 2010b, 2015b,c, 2017).

The analysis in this paper is compositional and avoids unusual semantic concepts such as index-driven and crosswise $\lambda$-abstraction (Zimmermann 2002b) or distributive polarity items (Oh 2001, 2006). It is placed in the context of algebraic event semantics and mereology (see Champollion \& Krifka 2016 for an overview). This allows us to formally model the relations between distribution over individuals and over events, as well as those between distribution over atoms and over nonatomic parts. In algebraic event semantics, the theory of distributivity operators developed by Link (1987) and extended by Schwarzschild (1996) requires adjustments for a number of reasons, discussed in Champollion 2016a. As the following examples show, the Neo-Davidsonian event semantic setting gives us the ability to think of the $\mathrm{D}$ and Part operators as being coindexable with different thematic roles. This allows us to capture through a simple change in coindexation the kinds of configurations that have otherwise been taken to require type-shifting-based reformulations of these operators (Lasersohn 1998):

(3) a. The first-year students [D [took an exam]].

Target: agent

b. John [D [gave a pumpkin pie]] to two girls.

Target: goal 
Overt distributivity in algebraic event semantics

The reformulation of the distributivity operators in Champollion 2016a provides the groundwork on which I build in this paper in order to formally relate this ambiguity to the one observable in examples like these:

(4) The boys told the girls two stories each.

Target: agent (two stories per boy)

(5) The boys told the girls two stories each. (two stories per girl)

Target: goal

To capture this and other parallels between covert and overt distributivity, I will propose that distance-distributive items across languages are in essence overt versions of the $\mathrm{D}$ and Part operators.

The theoretical picture that has been sketched so far, and that is developed below and in Champollion 2016a, provides us with a way to formulate commonalities and differences across instances of distributivity in natural language. Individual elements can be analyzed as being hardwired for certain parameter values, so that, for example, the difference between Link's and Schwarzschild's operators, as well as that between each and jeweils, can be described in terms of whether the value of the granularity parameter is prespecified to Atom or can be filled in by context. In this way, overt and covert instances of distributivity fit together and into distributivity theory more generally.

To develop this picture, Section 2 starts by describing relevant facts and generalizations about overt instances of distributivity across languages, drawing largely on the crosslinguistic discussion in Zimmermann 2002b. Overt and covert distributivity are brought together in Section 3, which develops a compositional account of overt distance distributivity. Section 4 deals with more complicated syntactic configurations, some of which previously lacked a compositional analysis. Section 5 extends the analysis to the determiners each and every, and shows that it accounts for their ability to take part in cumulative readings and to interact with nondistributive event modifiers. The way in which meanings of overt distributive items vary across languages is explained in Section 6. Section 7 compares the present analysis with Zimmermann 2002b, and Section 8 concludes. 
Lucas Champollion

\section{Overt distributivity across languages}

Distributive items have different syntactic uses and different meanings across languages. In English, the distributive quantifier each can be used in at least three ways, which I will refer to as adnominal, adverbial, and determiner each respectively:

(6) a. Adnominal: Two men have carried three suitcases each.

b. Adverbial: Two men have each carried three suitcases.

c. Determiner: Each man has carried three suitcases.

There are many terms for these three uses. Adnominal each has also been called shifted (Postal 1974), an anti-quantifier (Choe 1987), binominal (Safir \& Stowell 1988), or ditransitive (Roberts 1987). Adverbial each has also been called floated (Choe 1987). Determiner each is also called prenominal (Safir \& Stowell 1988). For the purpose of this paper, I set aside the use of each in other constructions, notably the reciprocal each other and the partitive each of the men. LaTerza $(2014 \mathrm{a}, \mathrm{b})$ connects all these constructions in a similar framework to the one I adopt in this paper. I will refer to the noun phrase two men in (6a) and (6b) as the antecedent (or target) of each, and to the noun phrase three suitcases in (6a) as the host of adnominal each.

I will refer to adnominal and adverbial each and to similar elements across languages as distance-distributive items. That term is taken from Zimmermann 2002b. There is a slight difference in terminology: Zimmermann reserves the term distance distributivity for adnominal elements, while I use it both for adnominal and for adverbial elements. This seems appropriate because adverbial each can be separated from its antecedent, for example by an auxiliary as shown in (6b).

Adnominal each can be shown by movement tests to form a constituent with its host noun phrase (Burzio 1986, Safir \& Stowell 1988). Distancedistributive items like it are sometimes seen as a challenge for compositional semantics, because their interpretations are similar to those of distributive determiners even though their surface syntactic structure appears to be fundamentally different (Oh 2001, 2006). For example, adnominal each in the object of sentence (6a) is contained in the constituent over which it seems at first sight to distribute, namely the verb phrase carried three suitcases each. This is of course similar to the challenge represented by quantifiers in object position (carried every suitcase), and the standard solutions to that challenge are available in both cases. For example, one can lift the type of 
the quantifier or the verb in order to give the quantifier scope over the verb phrase (Hendriks 1993, Barker 2002). I will follow the same general strategy in the formal analysis which follows. In fact, we will see that the scope of adnominal each is even more restricted than that of object quantifiers, because it does not include the verbal projection.

As we saw in (4) and (5), adnominal each can target different antecedents. This dependency is generally regarded as a case of ambiguity rather than underspecification. The ambiguity view finds support in analogous constructions involving dependent numerals in American Sign Language, where anaphoric dependencies are realized overtly (Kuhn 2015). Further support comes from the fact that in some languages, adnominal distance-distributive items must agree with their antecedents. There are syntactic constraints on the distribution of adnominal each with respect to its antecedent, such as c-command requirements and clausemate conditions. Accordingly, the dependency has been variously argued to be similar to that of reflexive pronouns with respect to their antecedents (Burzio 1986, Safir \& Stowell 1988) or to that of traces of noun phrases that undergo raising with respect to these noun phrases (Sportiche 1988). Similarly, adverbial each has been variously claimed to be related to its antecedent by movement, in the sense that it modifies the trace of its antecedent, or to be base-generated, in which case its relation to its antecedent can be taken to be anaphoric. For an overview of these conflicting claims and their implications, see Bobaljik 2001.

I will not add to the discussion on these syntactic constraints. Since the nature of the dependency between adnominal and adverbial each and their antecedents is not the focus of this paper, I will not take a strong position on it. In the formal theory to be developed in this paper, I will represent it by coindexing distance-distributive items with thematic roles, in the same way as I have coindexed covert distributivity operators with thematic roles in Champollion 2016a. More specifically, I will assume that thematic roles are introduced into the compositional derivation by $\theta$-role heads, and that distance-distributive items in certain languages including English must be coindexed with a $\theta$-role head in their clause. Accordingly, I will refer to this coindexation as $\theta$-indexing.

I assume that $\theta$-indexing is similar to other dependencies that are commonly formalized by coindexation, for example those between reflexive pronouns and their antecedents, in that it is subject to binding-theoretic constraints (Chomsky 1981, Büring 2005). In assuming that $\theta$-indexing is binding-theoretic in nature, I follow previous semantic analyses that inter- 
pret adnominal each without any movement, such as Zimmermann 2002b. Should the movement-based view turn out to be the correct one instead, the syntax-semantics interface may need to be modified accordingly, for example by incorporating elements from the theory of Cable 2014.

Turning now to other languages, adnominal and adverbial each can be translated in German by the word jeweils (Moltmann 1997, Zimmermann 2002b). Determiner each, however, must be translated by another word, jeder. Here and throughout the paper, I gloss distance-distributive items as DIST rather than EACH or EVERY since in some cases they have a wider range of readings than each. Sometimes they mean each, sometimes their meaning is closer to each time or on each occasion. Example (7a) is adnominal, example (7b) is adverbial, and example (7c) contains a determiner. Though adverbial and adnominal jeweils take the same surface position in (7a) and (7b), they can be teased apart syntactically, as discussed in Zimmermann 2002b.

(7) a. Die Jungen haben [jeweils [drei Koffer]] getragen. The boys have DIST three suitcases carried 'Each of the boys has carried three suitcases.' / In certain contexts: 'The boys have carried three suitcases each time.'

b. Die Jungen haben [jeweils [drei Koffer getragen]]. The boys have DIST three suitcases carried (As above.)

c. Jeder/*Jeweils Junge hat drei Koffer getragen. Each.SG.M/DIST boy has three suitcases carried 'Each boy carried three suitcases.'

(German)

As we will see, each and jeweils generalize to two classes of distancedistributive items across languages. Each-type distance-distributive items can also be used as determiners. Jeweils-type distance-distributive items cannot double as determiners, as shown in (7) for jeweils itself. Some languages have distance-distributive items which can also function as distributive determiners, as in English, and others are like German in that they have no such elements (Zimmermann 2002b). Partly building on earlier typological work (e.g., Gil 1982), Zimmermann observes that distance-distributive items which can also be used as determiners (e.g., each) always distribute over individuals, as determiners do. In contrast, those distance-distributive items which are formally distinct from determiners can typically also distribute over salient occasions, that is, over chunks of time or space. 
Overt distributivity in algebraic event semantics

The range of crosslinguistic variation can be illustrated by comparing English each with German jeweils, a distance-distributive element which cannot double as a distributive determiner. Jeweils can distribute over individuals like English each, but also over spatial or temporal occasions, as long as context provides a salient set of such occasions (Gil 1993, 1995, Moltmann 1997, Zimmermann 2002b). I call this the occasion reading. It corresponds to what is also called the temporal key reading and the spatial key reading (Balusu 2005, Balusu \& Jayaseelan 2013). I will treat the temporal and spatial cases as two separate readings (and I will focus on the temporal case). I leave the question open whether they should be treated as special cases of one reading. Another, less theory-neutral term for the occasion reading is event-distributive reading (Oh 2001, 2006). Zimmermann 2002b uses the term adverbial reading for it. This term is potentially misleading, because it suggests that only the adverbial use of jeweils can give rise to this reading. But adnominal jeweils can give rise to it as well (Zimmermann 2002b: Chapter 5). For example, in (8), jeweils is part of the subject noun phrase (we know this because German as a V2 language allows only one constituent before the tensed verb standen) and is therefore adnominal. However, as shown by the paraphrase, this instance of jeweils distributes over occasions, not over individuals.

(8) Jeweils zwei Jungen standen Wache.

DisT two boys stood watch

'Each time, two boys kept watch.'

(German)

The examples in (9) illustrate the occasion reading. Sentence (9) is ambiguous between a reading that distributes over individuals - the ones of which their plural subject consists, (9a) - and one that distributes over occasions (9b).

(9) Die Jungen haben jeweils zwei Affen gesehen.

The boys have DisT two monkeys seen

a. 'Each of the boys has seen two monkeys.'

b. 'The boys have seen two monkeys each time.'

(German)

While the former reading is always available, the latter requires a supporting context. That is, when (9) is uttered out of the blue, it only has the reading (9a). The occasion reading (9b), by contrast, is only available in contexts where there is a previously mentioned or otherwise salient set of occasions, 
such as contexts in which the boys have been to the zoo on several previous occasions.

Unlike each, jeweils can also occur with a singular subject, as in (10), repeated here from (2), which only has an occasion reading.

(10) Hans hat jeweils zwei Affen gesehen.

Hans has DisT two monkeys seen

'Hans has seen two monkeys on each occasion.'

(German)

This sentence is odd out of the blue, and it requires supporting context in the same way as reading (9b) does. Its other potential reading would involve vacuous distribution over only one individual, Hans. This is presumably blocked through the Gricean maxim of manner "Be brief" or a nonvacuity presupposition or implicature or whatever else prevents vacuous distributivity (Roberts 1987: 219). For more on this point, and for a fuller discussion of the kinds of noun phrases that can license adnominal each in English, see Champollion 2015a.

In the presence of contextual cues, jeweils is also able to distribute over nonatomic entities such as contextually salient groupings of atomic individuals:

(11) Beim Zoobesuch wurden die Jungen in Fünfergruppen

At.the zoo.visit were the boys in quintuplet.groups

aufgeteilt. Die Jungen sahen jeweils zwei Affen.

divided The boys saw DIST two monkeys

'During the zoo visit, the boys were divided up into groups of five. Each of the boys (or: of the groups) saw two monkeys.' (German)

In this example, jeweils can be understood in two ways. Depending on how this ambiguity is resolved, the truth conditions require two monkey sightings per boy or per group of five boys. As discussed in Champollion 2016a, I follow Schwarzschild 1996 in treating such pluralities as salient nonatomic entities, rather than as "group atoms" in the sense of Landman 1989. This allows me to treat jeweils on par with the Part operator in Schwarzschild 1996, which also requires salience when it distributes over nonatomic entities. That operator is anaphoric on a contextually salient cover over the plurality in question, that is, a set of salient (and potentially plural) entities whose sum is that plurality.

The previous example suggests that a grouping of contextually salient pluralities (or occasions) is sufficient for nonatomic interpretations of jeweils. 
Overt distributivity in algebraic event semantics

In fact, it is a prerequisite. Out of the blue, jeweils is not able to distribute over nonatomic entities. This can be seen in sentence (12), which is based on an example in Gillon 1987:

(12) Rodgers, Hammerstein und Hart haben jeweils ein Musical Rodgers, Hammerstein, and Hart have DIST a musical geschrieben.

written

'Rodgers, Hammerstein, and Hart each wrote a musical.' (German)

Out of the blue, (12) entails that each of the three composers wrote a musical, and cannot be interpreted as true in a scenario where Rodgers and Hammerstein wrote a musical together, Rodgers and Hart wrote another musical together, and no other musicals were written (see Champollion 2016a for discussion of this scenario). In other words, the mere existence of a nonatomic cover is not sufficient to make a jeweils sentence true. If (12) is uttered out of the blue, such a cover is not salient, and the putative reading on which the sentence would be true does not arise.

Given an appropriate context, jeweils can also distribute within the mass domain. This can be seen in example (13), a variant of an example discussed in connection with the Part operator in Champollion 2016a: §3:

(13) Auf der Party wurden Milch und Limonade angeboten. Milch kostete At the party were milk and lemonade offered Milk cost jeweils fünfzig Cent und Limonade kostete jeweils einen Euro. DisT fifty cent and lemonade cost DIST one euro 'At the party, they sold milk and lemonade. Milk cost fifty cents, and lemonade cost one euro.'

(German)

The predicates in question are distributed to a contextually salient level, namely the units in which the beverages are sold. (The last three examples were suggested by a reviewer.)

While jeweils allows distribution both over individuals and over salient nonatomic entities, this is not the case for all distance-distributive items (Zimmermann 2002b). Across languages, many adnominal distance-distributive items can only distribute over individuals. For example, English adnominal each lacks the occasion reading:

(14) The boys saw two monkeys each.

a. Available: 'Each of the boys saw two monkeys.' 
b. Unavailable: 'The boys saw two monkeys on each occasion.'

When adnominal each is used in a sentence whose subject is singular, distribution over individuals is not possible, presumably for pragmatic reasons as mentioned:

(15) *John saw two monkeys each.

Unlike (10), this sentence lacks an occasion reading, even with supporting context. To make the occasion reading surface, one cannot just provide temporal antecedents, as in (16a). Instead, one must add an overt noun like time as a complement of each, as in (16b).

a. *Yesterday and today John saw two monkeys each.

b. John saw two monkeys each time.

We have seen that English each also differs from German jeweils in that only the former can also be used as a determiner. Coming back to what I mentioned at the beginning of this section, Zimmermann postulates the following crosslinguistic generalization (Zimmermann 2002b):

(17) Zimmermann's generalization

All each-type distance-distributive items (i.e., those that can also be used as determiners) can only distribute over individuals. This contrasts with jeweils-type distance-distributive items, many of which can also distribute over salient spatial or temporal occasions.

This generalization is based in part on the following examples, which show that Albanian, Dutch, French, Icelandic, Italian, Japanese, Norwegian, Portuguese, Russian, and possibly Latin all have distance-distributive items that behave like English each in two ways: they can also be used as distributive determiners, and they lack the occasion reading, except in some cases when an extra noun with the meaning time (in the sense of occasion) is added. Many of the following examples are from Zimmermann 2002b.

Fëmijët blenë secili dy salsiçe. Children.DEF.NOM buy.AOR.3PL DIST.NOM two sausages 'The children bought two sausages each.'

$(\text { Albanian })^{1}$

1 Examples (18) through (20): Bujar Rushiti, p.c. to the author. 
Overt distributivity in algebraic event semantics

(19) Secili fëmijë ka blerë nga dy salsiçe.

DIST.NOM child.SG.NOM has bought DIST two sausages

'Each child bought two sausages.'

(Albanian)

(20) *Beni ka blerë secili dy salsiçe.

Ben.NOM has bought DisT.NOM two sausages

Intended: 'Ben bought two sausages each time.'

(Albanian)

(21) De jongens hebben elk twee boeken gelezen.

the boys have DisT two books read

'The boys have read two books each.'

$(\text { Dutch })^{2}$

(22) Elke jongen heeft twee boeken gelezen.

DisT boy has two books read

'Each boy has read two books.'

$(\text { Dutch })^{3}$

(23) Hans heeft elke *(keer) twee boeken gelezen.

Hans has DisT time two books read

'Hans has read two books each time.'

(Dutch) $)^{4}$

(24) Les professeurs ont lu deux livres chacun/chaque.

the professors have read two books DisT

'The professors have read two books each.'

(French) $)^{5}$

(25) Chaque professeur a lu deux livres.

DIST professor has read two books

'Each professor has read two books.'

$(\text { French })^{6}$

(26) Pierre a lu deux livres chaque *(fois) / *chacun(e) (fois).

Pierre has read two books DisT time / DIST time

'Pierre read two books each time.'

(French) $)^{7}$

(27) Strákarnir keyptu tvær pylsur hver.

the.boys bought two sausages DIST

'The boys bought two sausages each.'

(Icelandic) $^{8}$

2 Zimmermann 2002b: 40.

3 Zimmermann 2002b: 44; corrections supplied by Floris Roelofsen, p.c. to the author.

4 Floris Roelofsen, p.c. to the author.

5 Tellier \& Valois 1993: 574, ex. 1a quoted in Zimmermann 2002b: 41. Chaque is colloquial as an adnominal. While French adnominal chacun and determiner chaque are not exactly identical, they are historically related and can still be considered formally identical (Grevisse 1980, Junker 1995, Zimmermann 2002b: 44, fn. 30).

6 Zimmermann 2002b: 44.

7 Author's judgment, adapted from Zimmermann 2002b: 47.

8 Examples (27) through (29): Meike Baumann, Daði Hafpór Helgason, Hildur Hrólfsdóttir, Sverrir Kristinsson, Gunnar Ingi Valdimarsson, p.c. to the author. 
Lucas Champollion

(28) Hver strákur keypti tvær pylsur.

DisT boy bought two sausages

'Each boy bought two sausages.'

(Icelandic)

(29) Pétur keypti tvær pylsur hvert *(sinn).

Pétur bought two sausages DisT time

'Pétur bought two sausages each time.'

(Icelandic)

(30) I ragazzi comprarono un libro ciascuno.

the boys bought a book DIST.SG.M

'The boys bought one book each.'

$(\text { Italian })^{9}$

(31) Ciascun ragazzo ha comprato due salsicce.

DIST.SG.M boy has bought two sausage.PL.F

'Each boy has bought two sausages.'

$(\text { Italian })^{10}$

(32) *Peter ha comprato due salsicce ciascun/-o/-e.

Peter has bought two sausage.PL.F DIST.SG.M/DIST.SG.M/DIST.PL.F

Intended: 'Peter has bought two sausages.'

$(\text { Italian })^{11}$

(33) Otoko-tati-ga sorezore huta-ri-no zyosei-o aisi-teiru koto.

men-PL-NOM DIST two-CL-GEN women-ACC love-ASP fact

'The fact that the men love two women each.' (Japanese) ${ }^{12}$

(34) Sorezore-no gakusei-ga iti-dai-no piano-o motiage-ta.

DIST-GEN student-NOM one-CL-GEN piano-ACC lift-PAST

'Each student lifted one piano.'

$(\text { Japanese })^{13}$

(35) Taroo-wa sorezore-?(de) iti-dai-no piano-o motiage-ta.

Taroo-TOP DIST(-LOC) one-CL-GEN piano-ACC lift-PAST

'Taroo lifted one piano on each occasion.'

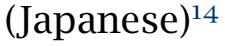

(36) Guttene har kjøpt to pølser hver.

the.boys have bought two sausages DisT

'The boys bought two sausages each.'

(Norwegian) $^{15}$

(37) Hver gutt har kjøpt to pølser.

DisT boy has bought two sausages

9 Burzio 1986: 198, ex. 5ob quoted in Zimmermann 2002b: 41.

10 Zimmermann 2002b: 44 .

11 Ivano Ciardelli, p.c. to the author.

12 Sakaguchi 1998: 115, ex. 1 quoted in Zimmermann 2002b: 41.

13 Sakaguchi 1998: 4, ex. 7.

14 Chigusa Kurumada, p.c. to the author. Kurumada comments that the sentence without de

feels like an elliptical version of the sentence with $d e$.

15 Øystein Vangsnes, p.c. to Zimmermann (2002b: 40). 
Overt distributivity in algebraic event semantics

'Each boy has bought two sausages.' $\quad$ (Norwegian) ${ }^{16}$

(38) Jon har kjøpt to pølser hver*(gang).

Jon has bought two sausages DisT time

'Jon has bought two sausages each time.'

$(\text { Norwegian })^{17}$

(39) Os meninos compraram duas linguiças cada (um).

The boys bought two sausages DisT (one)

'The boys bought two sausages each.'

(Portuguese) $^{18}$

(40) Cada menino comprou duas linguiças.

Dist boy bought two sausages

'Each boy bought two sausages.'

(Portuguese) $^{19}$

(41) João comprou duas linguiças cada *(vez).

João bought two sausages DisT time

'João bought two sausages each time.'

(Portuguese) $^{20}$

(42) Mal'chiki kupili po dve sosiski kazhdyj.

boys.NOM buy.PFV.PAST.PL DIST two sausage DIST

'The boys bought two sausages each.'

$(\text { Russian })^{21}$

(43) Kazhdyj mal'chik kupil dve sosiski.

DisT boy buy.PFV.PAST.M.SG two sausage

'Each boy bought two sausages.'

$(\text { Russian })^{22}$

(44) Kazhdyj*(raz) Petja pokupal dve sosiski.

DisT (time) Petja buy.IPFV.PAST.M.SG two sausage

'Each time, Petya bought two sausages.'

$(\text { Russian })^{23}$

To this list we may tentatively add Latin quisque 'each, any', which is described as lacking the occasion reading (Bortolussi 2013: 13, fn. 11) and which can function both as a distance-distributive item and as a determiner:

16 Zimmermann 2002b: 44 .

17 Kjell Johan Sæbø, p.c. to the author.

18 Examples (39) through (41): Luciana Meinking Guimarães and Leonor Remédio, p.c. to the author. This example is given in Brazilian Portuguese. In European Portuguese, boy(s) would be translated more commonly as rapaze(s).

19 Brazilian Portuguese. See note 18.

20 Brazilian Portuguese. See note 18. In European Portuguese, this would be translated as $O$ João comprou duas linguiças de cada *(vez).

21 Olga Borik, p.c. to Zimmermann (2002b: 41). On po, see also examples (63) through (65).

22 Olga Borik, p.c. to Zimmermann (2002b: 44).

23 Masha Esipova and Sonia Kasyanenko, p.c. to the author. 
Lucas Champollion

(45)
duo quisque
Alpina
coruscant /
two.N DiST.NOM.SG.M Alpine.NOM.PL.N sparkle.3PL.SG /
gaesa
manu
javelin.NOM.PL.N hand.ABL.SG.F
'in each man's hand two Alpine javelins gleamed'

$(\text { Latin })^{24}$

(46)

quod quisque imperator habeat

what DIST.NOM.SG.M general.NOM.SG.M have.3SG.PRES.SUBJ

pecuniae

money.GEN.SG.F

'whatever money each/any general has'

$(\text { Latin })^{25}$

Zimmermann's generalization states that every distance-distributive item that can be used as a determiner lacks the occasion reading. This is an implicational universal, not a biconditional. The opposite direction would be true if every distance-distributive item that lacks the occasion reading could be used as a determiner. Zimmermann considers Japanese as a counterexample to this opposite direction, but whether this is correct is not very clear. Zimmermann bases his view on the fact that the Japanese distance-distributive item sorezore differs formally from what he calls the Japanese distributive determiner-quantifier wh...+mo, which is illustrated in (47).

(47) Dono gakusei-mo sooseezi-o hutatu katta.

which student-Mo sausage-ACC two-CL bought

'Every student bought two sausages.'

$(\text { Japanese })^{26}$

However, sorezore can also be used in the position of a determiner, as example (34) above shows. The syntactic status of sorezore in this example, and therefore the import of Japanese on Zimmermann's generalization, is debatable since Japanese is usually assumed to lack overt determiners. For a detailed semantic analysis of sorezore, see Sakaguchi 1998: Chapter 3.

Setting sorezore aside, the inverse of Zimmermann's generalization seems to hold for many languages. That is, when adnominal distance-distributive items cannot be used as determiners, they tend to have occasion readings. In addition to German jeweils, adnominal distance-distributive items that belong to this class are found in Bulgarian, Czech, Korean, Polish, Romanian, and Russian. Many of these observations are due to Zimmermann (2002b).

24 Vergil, Aeneid 8, 660-661, Bortolussi 2013: 6. The slash stands for a line break in the Aeneid. 25 Cicero, De Lege Agraria 1.10.8; see also Spevak 2014: 51.

26 Satoshi Tomioka, p.c. to Zimmermann (2002b: 45). 
Overt distributivity in algebraic event semantics

The Korean case is discussed in depth by Choe (1987) and by Oh (2001, 2006), and the Polish case by Piñón (2000) and by Przepiórkowski (2013, 2014a,b, 2015).

(48) John i Mary kupiha po edna tetradka. John and Mary bought DisT one notebook 'John and Mary bought one notebook each.' $\quad$ (Bulgarian) ${ }^{27}$

(49) Vsjako/*Po momče kupi dve nadenici. DisT boy bought two sausages 'Each boy bought two sausages.' (Bulgarian) $^{28}$

(50) Mary byaga po 5 mili predi zakuska. Mary runs DIST 5 miles before breakfast 'Mary runs five miles before breakfast (every morning).' (Bulgarian)29

(51) Chlapci koupili po dvou párcích/párkách. boys bought DisT two sausages.LOC 'The boys bought two sausages each.'

(52) Každý/*Po chlapec koupil dva párky. DisT boy bought two sausages 'Each boy bought two sausages.'

(53) Po třech ženách vstupovalo do místnosti.

DisT three.LOC women.LOC entered.3SG into room '[Each time,] three women entered the room.'

(54) Ai-tul-i phwungsen hana-ssik-ul sa-ess-ta. child-PL-NOM balloon one-DIST-ACC bought 'The children bought one balloon each.'

(55) Sonyen-mata chayk-ul twu kwen-ssik sa-ess-ta. boy-DisT book-ACC two CL-DIST bought 'Every boy bought two books.'

27 Petrova (2000) quoted in Zimmermann 2002b: 47.

28 Milena Petrova, p.c. to Zimmermann (2002b: 45); corrections supplied by Roumyana Pancheva, p.c. to the author.

29 Petrova (2000: ex. 3b) quoted in Zimmermann 2002b: 47.

3o Hana Filip, p.c. to Zimmermann (2002b: 41).

31 Hana Filip, p.c. to Zimmermann (2002b: 45) and to the author.

32 Hana Filip, p.c. to Zimmermann (2002b: 47) and to the author.

33 Choe (1987: 49, ex. 13) quoted in Zimmermann 2002b: 41; corrections supplied by WooJin

Chung and Songhee Kim, p.c. to the author.

34 Kim, p.c. to Zimmermann (2002b: 45); corrections supplied by WooJin Chung and Songhee

Kim, p.c. to the author. 
Lucas Champollion

(56) Na-nun phwungsen hana-ssik-ul sa-ess-ta.

I-TOP balloon one-DisT-ACC bought

'I bought a balloon (each time / each day / at each store).' (Korean) ${ }^{35}$

(57) Chłopcy kupili po dwie kiełbaski.

Boys bought Dist two sausages

'The boys bought two sausages each.' $\quad$ (Polish) ${ }^{36}$

(58) Każdy/*Po chłopak kupił dwie kiełbaski.

DisT boy bought two sausages

'Each boy bought two sausages.'

$(\text { Polish })^{37}$

(59) Papież zwiedzał po trzy kraje.

Pope visited DisT three countries

'The pope visited three countries each time.'

$(\text { Polish })^{38}$

(6o) Doi oameni au cărat cîte trei valize.

two men have carried DisT three suitcases

'Two men have carried three suitcases each.'

(Romanian) $)^{39}$

(61) Fiecare/*Cîte om cară trei valize.

DIST man carry-PRES.3SG three suitcases

'Each man is carrying three suitcases.'

(Romanian) $)^{40}$

(62) Un om cară cîte trei valize.

one man carry-PRES.3SG DIST three suitcases

'One man carries three suitcases each time.'

$(\text { Romanian })^{41}$

(63) Mal'chiki kupili po dve sosiski.

boys buy.PFV.PAST.PL DIST two sausages

'The boys bought two sausages each.' $\quad$ (Russian) ${ }^{42}$

(64) Kazhdyj/*Po mal'chik kupil dve sosiski.

DisT boy buy.PFV.PAST.M.SG two sausages

'Each boy bought two sausages.'

(Russian) $)^{43}$

35 Choe (1987: 52, ex. 18) quoted in Zimmermann 2002b: 47; corrections supplied by WooJin

Chung and Songhee Kim, p.c. to the author.

36 Adam Przepiórkowski, p.c. to the author.

37 Adam Przepiórkowski, p.c. to the author.

38 Przepiórkowski 2014a: 110.

39 Gil 1982: 18, ex. 1f, Zimmermann 2002b: 41, Gil 1993: 298, ex. 66b.

40 Gianina Iordăchioaia, p.c. to the author. See also Brasoveanu \& Farkas (2011: 10).

41 Gil 1993: 298, ex. 66a, Gianina Iordăchioaia, p.c. to the author. See also Iordăchioaia \& Soare

2015: §4.

42 Masha Esipova, p.c. to the author.

43 Masha Esipova, p.c. to the author. See also example (43). 
Overt distributivity in algebraic event semantics

(65) Petja pokupal po dve sosiski.

Petya buy.IPFV.PAST.M.SG DIST two sausages

'Petya bought two sausages on each occasion.' $\quad$ (Russian) ${ }^{44}$

Since Zimmermann's generalization is not about languages but about items, it can sometimes be observed within one language. I have illustrated this by including examples (42) through (44), which show that Russian kazhdyj can be used as a determiner and lacks the occasion reading, as well as examples (63) through (65), which show that Russian po has the occasion reading and cannot be used as a determiner.

Many languages express adnominal distance distributivity by a bound morpheme that attaches to a numeral - most commonly, a reduplicative morpheme (Gil 1982, 1993, 2013). The import of this fact for Zimmermann's generalization is unclear, since bound morphemes are not expected to be able to act as determiners, hence their inability to do so is not surprising. I mention it here for completeness and because the compositional analysis given below extends to these morphemes. On the one hand, we find cases where reduplication does not give rise to occasion readings, such as Hungarian (Farkas 1997, Szabolcsi 2010):

A gyerekek két-két majmot láttak.

The children two-two monkey.Acc saw.3PL

a. Available: 'Each of the children saw two monkeys.'

b. Unavailable: 'The children saw two monkeys each time.'

(Hungarian) $^{45}$

On the other hand, we find cases where bound morphemes do give rise to occasion readings, such as the reduplicative morphemes in Hausa (Zimmermann 2008), Karitiana (Müller \& Negrão 2012) and Telugu (Balusu 2005, Balusu \& Jayaseelan 2013) and the suffix in Tlingit (Cable 2014). All these cases are illustrated here and discussed in detail in their respective sources. For more examples and a typological overview, see Gil 1995, 2013.

(67) yâaraa bìyar̃ bìyar̃ sun zoo.

children five five 3PL.PERF come

a. 'The children came in groups of five.'

44 Masha Esipova, p.c. to the author.

45 Szabolcsi 2010: 138, ex. 99. 
Lucas Champollion

b. 'On each occasion, five children came.' $\quad$ (Hausa) ${ }^{46}$

(68) Audù yaa sàyi lèemoo ukù ukù.

Audu 3SG.PERF buy orange three three

'Audu bought oranges in threes.'

$(\text { Hausa })^{47}$

(69) Sypomp sypomp nakam'at gooj õwã.

two-OBL two-OBL 3-DECL-CAUS-build-NFUT canoe child

a. 'Each child built two canoes.'

b. 'On each occasion, children built two canoes.' (Karitiana) ${ }^{48}$

(70) pilla-lu renDu renDu kootu-lu-ni cuus-ee-ru.

kid-PL two two monkey-PL-ACC see-PAST-3PL

a. 'The kids each saw two monkeys.'

b. 'The kids saw two monkeys each time.'

c. 'The kids saw monkeys in groups of two.'

(Telugu $)^{49}$

(71) Nás'gigáa xáat has aawasháat. three.DIST fish PL.3OBJ.PFV.3SUBJ.catch
a. 'They caught three fish each.'
b. 'They caught three fish each time.'
(Tlingit) $)^{50}$

The facts discussed in this section suggest the following requirements for a semantic analysis of distance distributivity. First, the synonymy of the determiner, adnominal and adverbial uses of each in English should be captured, ideally by essentially identical lexical entries. Second, the fact that distance-distributive items across languages share some part of their meanings (namely their individual-distributive readings) should be represented, as well as the fact that some of them can also have occasion readings in suitable contexts. Third, the analysis should clarify the connections between distance-distributive items and distributivity theory more generally, and should capture the semantic variation across distance-distributive items. Finally, an explanation should be readily available for the crosslinguistic observation that distance-distributive items that can also be used as deter-

46 Zimmermann 2008: 462, ex. 98a.

47 Zimmermann 2008: 462, ex. 98b.

48 Müller \& Negrão 2012: 160. The authors note that Karitiana bare nouns are number-neutral and not specified for definiteness.

49 Balusu \& Jayaseelan 2013: 67, ex. 15a.

5o Cable 2014: 564, ex. 3b. 
Overt distributivity in algebraic event semantics

miners can only distribute over individuals (Zimmermann's generalization). The rest of the paper develops an analysis that fulfills these requirements.

The analysis I will propose is semantic, and does not aim to explain crosslinguistic differences that are syntactic in nature. For example, Englishtype languages are less likely to allow for the inverse distribution of subject over object denotations than some German-type languages are:

(72) *One journalist each interviewed the politicians.

(73) Jeweils ein Journalist interviewte die Politiker. DIST one journalist interviewed the politicians

'The politicians were interviewed by one journalist each.' (German)

See Zimmermann 2002b: §5.4.2, §5.4.3 for an extensive discussion and an integrated syntactic and semantic approach. My own account does not specify the syntactic constraints that govern the $\theta$-indexing of distributivity operators. A separate theory of $\theta$-indexing could be developed to account for the locality constraints on adnominal each constructions. These conditions have been studied in detail (e.g., Burzio 1986, Safir \& Stowell 1988, Zimmermann 2002b: Chapter 3). Other examples of coindexation that are subject to syntactic locality constraints are familiar from binding theory (Chomsky 1981, Büring 2005). The crosslinguistic variation on locality conditions is also discussed in Section 4.3.

\section{Relating overt and covert distributivity}

The connection between the D operator from Link 1987 and adverbial each that was illustrated in (1) has been noted many times. I take adverbial and adnominal each and related distance-distributive items in Albanian, Dutch, French, Icelandic, Italian, Japanese, Norwegian, Portuguese, Russian, and possibly Latin to be essentially D operators. These are the languages mentioned in Section 2 as being English-type. As for jeweils and its relatives in German-type languages like Bulgarian, Czech, Korean, Polish, Romanian, and Russian, we have seen that they can distribute over spatial and temporal intervals - arguably nonatomic entities. Link's D operator always distributes down to individual atoms and can therefore not be extended to these cases. I will connect them to the nonatomic distributivity operator Part from Schwarzschild 1996. For the sake of brevity, I will only execute the analysis for English each and German jeweils, but it should be clear how to extend it to other 
distributive items depending on which one of these two they pattern with. I will only show how to model the individual-distributive and the temporal occasion readings. The extension from the temporal to the spatial occasion reading is straightforward.

The guiding idea of the analysis is that overt distributive items include two versions of the distributivity operator. Each includes the atomic distributivity operator $\mathrm{D}$, which can distribute only over count domains because only those domains have atoms. Jeweils includes the nonatomic distributivity operator Part. I argue in Champollion 2016a that the latter operator can also distribute over noncount domains like time. I adopt the strata-theoretic perspective from Champollion 2010b, 2015c. According to this theory, distributivity is a property with two parameters: dimension and granularity. I will suggest that each, just like the D operator, comes prespecified for "granularity=atom". This blocks the setting "dimension=time", hence distributivity over occasions is unavailable. By contrast, jeweils does not come prespecified for anything but is anaphoric on the context. It can therefore distribute over salient covers, or salient stretches of time, just like the Part operator.

In claiming that each is an overt form of the D operator, I loosely follow proposals made for German jeweils and its short form je by Link (1987, 1998b) and for English each by Roberts (1987). While Link and Roberts did not give explicit compositional implementations and did not fully consider the crosslinguistic picture, this paper can be seen as an update to their ideas which benefits from later work on algebraic semantics, nonatomic distributivity, and compositional implementations.

Arriving at the meaning of each from the meaning of distributivity operators is somewhat the reverse of the process by which Schwarzschild arrived at his Part operator, which "was based on a generalization of Dowty \& Brodie's (1984) account of floated quantifiers as verb phrase modifiers" (Schwarzschild 1996: 137). Schwarzschild himself notes that the history of Part should not be taken for an endorsement that floated quantifiers are related to it, and argues that floated quantifiers should be distinguished from distributivity operators because he takes reciprocals to be licensed by distributivity operators, but not by adverbial each. He gives the examples in (74) to support this claim. These kinds of examples, as well as the idea that reciprocals are licensed by distributivity operators of some kind or other, go back to Heim, Lasnik \& May 1991.

(74) a. They ${ }_{j} \operatorname{Part}_{i}\left[\right.$ saw each other $\left.{ }_{j, i}\right]$. 
Overt distributivity in algebraic event semantics

b. ${ }^{*}$ They $_{j}$ each $_{i}$ saw each other ${ }_{j, i}$.

Schwarzschild's argument rests on the assumption that reciprocals are licensed by VP-level distributivity operators. But then we should expect that all VPs with reciprocals in them are interpreted distributively, contrary to fact (see Dotlačil 2013 and references therein):

(75) a. John and Mary wrote to each other on two cold days. ?? under the reading 'John wrote to Mary on two cold days and Mary wrote to John on two other cold days’ (Moltmann 1992)

b. The doctors gave each other a new nose. ?? under the reading 'each doctor gave the other doctor a different new nose'

(E. Williams 1991)

c. The two children gave each other a Christmas present. ?? under the reading 'each child giving a different present'

(E. Williams 1991)

Since neither overt nor covert adverbial distributive operators seem to be able to license reciprocals, nothing stands in the way of a unified analysis, to which I turn now.

I will adopt the framework of Champollion 2016a, including the following assumptions: singular count nouns involve reference to atoms, thematic roles are cumulative partial functions, verbs are cumulative event predicates. I use the following typing conventions: $t$ for truth values, $e$ for ordinary objects, $v$ for events, and $i$ for times. The symbols $x, y, z, x^{\prime}, y^{\prime}, z^{\prime}$ and so on stand for variables that range over ordinary objects, and the symbols $e, e^{\prime}, e^{\prime \prime}$, for events. I use $P$ for (variables that range over) predicates of type $\langle e, t\rangle, V$ for predicates of type $\langle v, t\rangle$, and $\theta$ as well as $\Theta$ for functions of type $\langle v, e\rangle$. Some variables range over objects of different types; when the types are clear from context, I will continue to use the symbols above. For example, the range of $\theta$ will also include runtime, a function from events to times. I assume that ordinary objects, events, and intervals are each closed under mereological sum formation (Link 1998a, Champollion \& Krifka 2016). Intuitively, this means that these categories include plural entities. The lowercase variables just mentioned should therefore be taken to range over both singular and plural entities. In the literature on plurals, the distinction between singular and plural entities is often indicated by lowercase and uppercase variables. Since almost all the variables in my representations range over potentially plural entities, I do not follow this convention. 
I assume that noun phrases are interpreted in situ, because I do not consider quantifier raising in this paper. Silent $\theta$-heads denote thematic roles, typically of type $\langle v, e\rangle$ (event to individual). These heads are located between noun phrases and verbal projections. The one that denotes the agent role can be either thought of as a silent case-marker-like part of the noun phrase, or as little $v$ or Voice, depending on whether it first combines with the subject noun phrase or with the verb phrase. The heads that denote the theme and goal roles bear some conceptual similarity with applicative heads (Pylkkänen 2008a). I will occasionally omit or abbreviate these heads in my LFs but they should always be assumed to be there. The precise nature of the compositional process is not essential, but it affects the types of the lexical entries of distance-distributive items so let me make it concrete. I assume that the following type shifters apply first to the $\theta$-head, then to the noun phrase, and finally to the verbal projection:

(76) a. Type shifter for definites: $\lambda \theta \lambda x \lambda e \cdot \theta(e)=x$

b. Type shifter for indefinites: $\lambda \theta \lambda P \lambda e . P(\theta(e))$

Each of these type shifters combines a noun phrase with its $\theta$-head to build an event predicate of type $\langle v, t\rangle$ which can combine with other predicates of the same type via intersection. These type shifters can easily be modified if one wishes to accommodate alternative theoretical assumptions, for example that the $\theta$-head combines first with the verbal projection and then with the noun phrase it belongs to. It does not matter for the purposes of this paper whether or not these type shifters are only inserted in the semantic derivation or also have silent syntactic counterparts; for a discussion of the differences between these two options, see Pylkkänen 2008b.

After the noun phrases the boys (definite) and two monkeys (indefinite) combine with the $\theta$-heads [agent] and [theme] via the type shifters in (76), their denotations are as follows.

(77) $\llbracket[$ agent $]$ the boys $\rrbracket=\lambda e[* \operatorname{agent}(e)=\bigoplus$ boy $]$

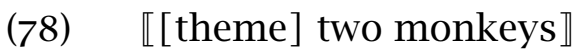

$$
=\lambda e\left[\mid * \text { theme }(e) \mid=2 \wedge{ }^{*} \operatorname{monkey}(* \text { theme }(e))\right]
$$

The notation in (78) might look surprising at first sight because it does not use an existential quantifier for the indefinite. That quantifier is implicit in the notation, however: ${ }^{*}$ monkey $\left({ }^{*}\right.$ theme $\left.(e)\right)$ is logically equivalent to $\exists x$.*monkey $(x) \wedge{ }^{*}$ theme $(e)=x$. 
Overt distributivity in algebraic event semantics

After the verb has combined with all its arguments, the event variable is existentially bound if the sentence is uttered out of the blue. If the sentence is understood as referring to a specific event, the event variable is instead resolved to that event. If the noun phrases combine directly with the verb, we get a scopeless reading as in (79). Here and below, I write two-monkeys as a shorthand for $\lambda x\left[|x|=2 \wedge{ }^{*} \operatorname{monkey}(x)\right]$ and similarly for other cases.

(79)【The boys saw two monkeys $\rrbracket$

$$
=\exists e\left[{ }^{*} \operatorname{agent}(e)=\bigoplus \text { boy } \wedge{ }^{*} \operatorname{see}(e) \wedge \operatorname{two}-m o n k e y s(* \text { theme }(e))\right]
$$

To generate distributive readings, we use Link's D operator, reformulated in Champollion 2016a and repeated here as (80). As explained there, I assume that the D operator is coindexed with the thematic role of its target.

\section{Definition: Event-based D operator}

$\llbracket \mathrm{D}_{\theta} \rrbracket \stackrel{\text { def }}{=} \lambda V \lambda e\left[e \in{ }^{*} \lambda e^{\prime}\left(V\left(e^{\prime}\right) \wedge \operatorname{Atom}\left(\theta\left(e^{\prime}\right)\right)\right)\right]$

As an example, the distributive reading of (79) is derived like this:

$$
\begin{aligned}
& \llbracket[[\text { agent }] \text { The boys }]\left[D_{\text {agent }}[\text { saw }[[\text { theme }] \text { two monkeys }]]\right] \rrbracket \\
& =\exists e\left[* ^ { * } \operatorname { a g e n t } ( e ) = \bigoplus \text { boy } \wedge e \in \left[\llbracket D _ { \text { agent } } \rrbracket \left(\lambda e ^ { \prime } \left[{ }^{*} \operatorname{see}\left(e^{\prime}\right) \wedge\right.\right.\right.\right. \\
& \left.\left.\left.\left.\operatorname{two}-m o n k e y s\left({ }^{*} \text { theme }\left(e^{\prime}\right)\right)\right]\right)\right]\right] \\
& =\exists e\left[{ } ^ { * } \operatorname { a g e n t } ( e ) = \bigoplus \text { boy } \wedge e \in { } ^ { * } \lambda e ^ { \prime } \left[{ }^{*} \operatorname{see}\left(e^{\prime}\right) \wedge\right.\right. \\
& \text { two-monkeys } \left.\left.\left({ }^{*} \operatorname{theme}\left(e^{\prime}\right)\right) \wedge \operatorname{Atom}\left(\operatorname{agent}\left(e^{\prime}\right)\right)\right]\right]
\end{aligned}
$$

This formula is true just in case there is an event $e$ whose agent is the boys, and which consists of seeing-two-monkeys events whose agents are atomic. As discussed in Champollion 2016a, the background assumptions of algebraic semantics ensure that the seeing-two-monkeys events have boys as agents even though the formula does not explicitly state this. I come back to this point at the end of this section.

Here are the entries for adverbial and adnominal each; determiner each is discussed in Section 5. An explanation follows. An illustration of the derivation of a basic sentence like The boys saw two monkeys each is shown in Figure 1. Adverbial each works similarly.

$$
\begin{aligned}
& \llbracket \text { each }_{\theta} \rrbracket_{\text {adverbial }}=\llbracket \mathrm{D}_{\theta} \rrbracket=(80) \\
& \llbracket \text { each }_{\theta} \rrbracket_{\text {adnominal }}=\lambda P \lambda \Theta \lambda e\left[e \in \llbracket \mathrm{D}_{\theta} \rrbracket\left(\lambda e^{\prime} . P\left(\Theta\left(e^{\prime}\right)\right)\right)\right]
\end{aligned}
$$




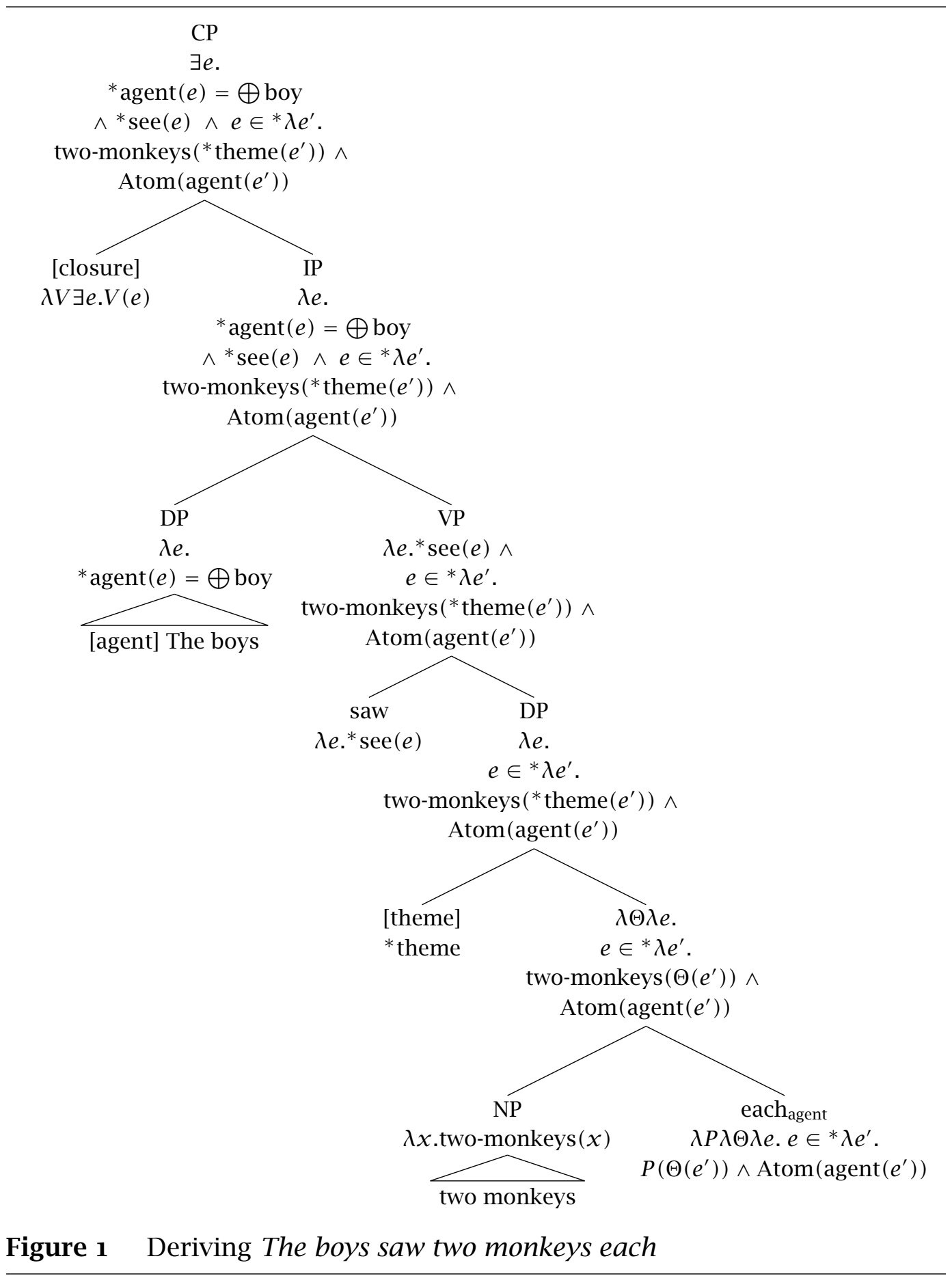


Overt distributivity in algebraic event semantics

I assume that adverbial each, as shown in (82), is a verb phrase modifier just like the $\mathrm{D}$ operator, and can therefore be given the same entry as that operator. I adopt for concreteness the assumption that adverbial each is an adverb adjoined to VP. This is similar to what has been argued for floating quantifiers in general by Dowty \& Brodie (1984), Bobaljik (1995) and Doetjes (1997). Another view analyzes floating quantifiers as the remaining part of a noun phrase the rest of which has moved away from it (e.g., Safir \& Stowell 1988, Sportiche 1988). The movement view makes a formal link between each and its antecedent available for independent reasons since there is a movement relation between them. The adverbial view leaves it open whether a formal link is created (for example via $\theta$-indexing, as I assume here for English each) or whether the target of each is determined in some other way, for example by choosing from a small inventory of thematic roles and similar functions. In Section 4.3, I consider this possibility for German jeweils.

On the present view, adverbial each is synonymous with the D operator, and adnominal each is essentially a type-shifted D operator. This captures the fact that they are essentially synonymous to each other. As shown in (83), adnominal each carries an index, which I assume is $\theta$-indexed with the thematic role of its antecedent, written as $\theta$. In the compositional derivation, adnominal each first combines with its host predicate $P$ (e.g., two monkeys), and then with the $\theta$-head of its host, written as $\Theta$ (not to be confused with the $\theta$-role of its antecedent). Afterwards, it combines intersectively with the verbal projection to which its host attaches (for example the verb see). This means that adnominal each takes scope over its complement but - unlike adverbial each - not over the verbal projection (Dotlačil 2011, 2012, LaTerza 2014a,b). A previous version of my theory, Champollion 2012, gave adnominal each scope over the verb phrase as well. This leads to wrong predictions as discussed in LaTerza 2014a,b, and has been fixed here. The problem can be illustrated with the minimal pair in (84) (LaTerza 2014b):

(84) a. John and Bill served [[four meals] each] to (exactly) three judges.

b. John and Bill [each [served four meals to (exactly) three judges]].

As LaTerza reports, speakers judge (84a) true of situations where there are at most three judges, while (84b) is true in situations which allow up to six different judges. This suggests that adnominal and adverbial each take scope as indicated by the square brackets in these examples. Sentence (84a) can be derived as in Figure 2. 
$\mathrm{CP}$

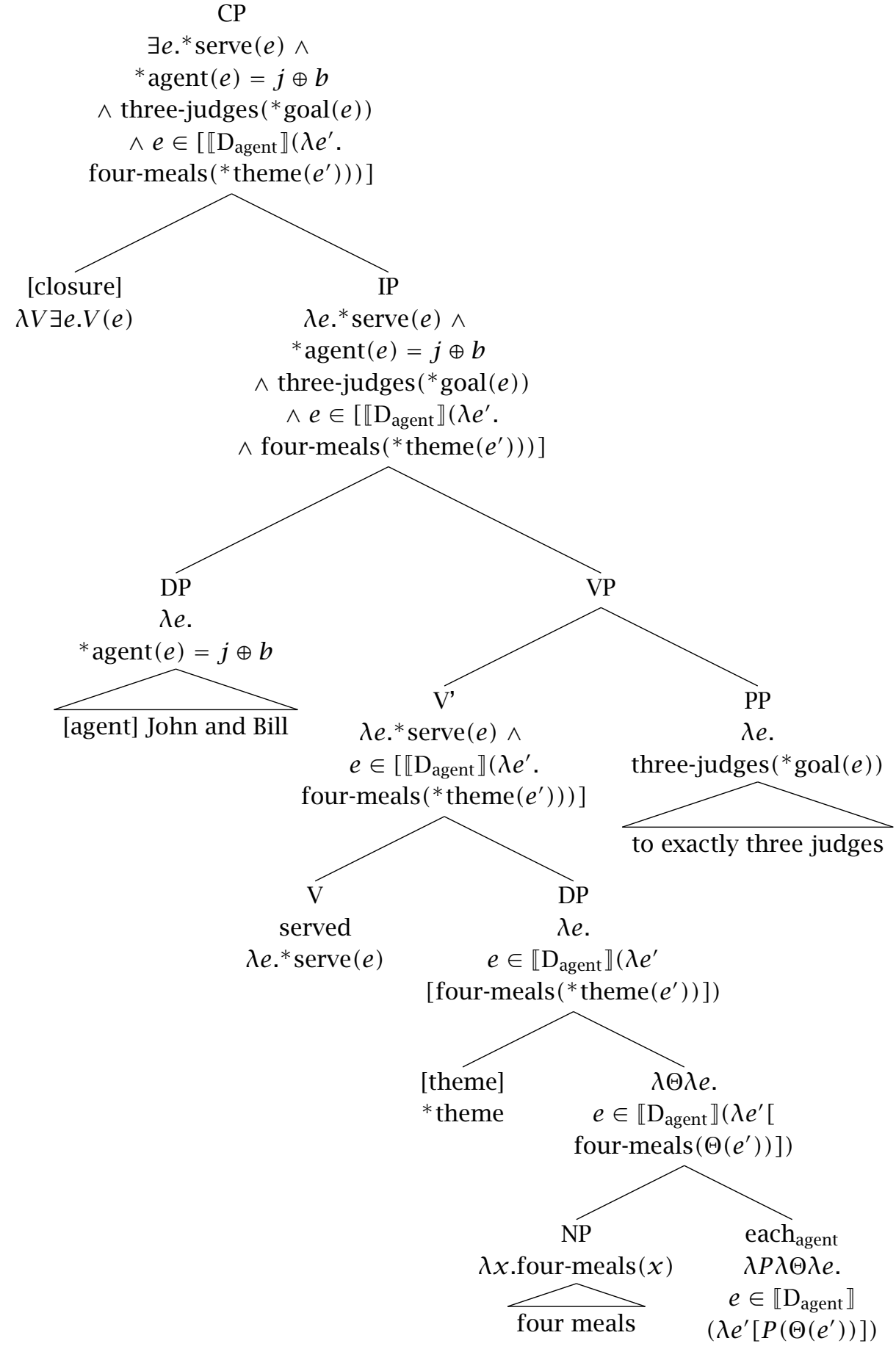

Figure 2 Deriving John and Bill served four meals each to exactly three judges 
Overt distributivity in algebraic event semantics

My entry for adnominal each combines with its host in two steps, in order to give it access to both the predicate and the $\theta$-head. This is not essential, but it allows us to ensure that the type of the predicate is $\langle e, t\rangle$. I do so to provide a hook on which to build future accounts of the "counting quantifier requirement" that prevents such phrases as *most men each (Safir \& Stowell 1988, Sutton 1993, Szabolcsi 2010: §10.5). The theory in this paper does not aim to provide an account of this requirement and will not rule out bare plurals as in *They saw monkeys each, as pointed out in Cable 2014. If an independent account of these kinds of mismatches can be provided that does not need separate access to the host predicate and its $\theta$-role, it may not be necessary to place each between the host predicate and the $\theta$-head after all.

Turning now to jeweils, my reformulation of the Part operator in Champollion 2016a, repeated here as (85), provides the basis for its lexical entries.

\section{Definition: Event-based Part operator \\ $\llbracket \operatorname{Part}_{\theta, \mathrm{C}} \rrbracket \stackrel{\text { def }}{=} \lambda V \lambda e\left[e \in{ }^{*} \lambda e^{\prime}\left(V\left(e^{\prime}\right) \wedge C\left(\theta\left(e^{\prime}\right)\right)\right)\right]$}

(Takes an event predicate $V$ and returns a predicate that holds of any event $e$ which can be divided into events that are in $V$ and whose $\theta \mathrm{s}$ satisfy the contextually salient predicate $C$.)

Adverbial jeweils is treated as in (86).

$$
\begin{aligned}
& \llbracket \text { jeweils }_{\theta, \mathrm{C}} \rrbracket_{\text {adverbial }} \\
& =\lambda V \lambda e\left[\llbracket \operatorname{Part}_{\theta, \mathrm{C}} \rrbracket(V)(e) \wedge(C \neq \text { Atom } \rightarrow \bigoplus C=\theta(e))\right] \\
& =\lambda V \lambda e\left[e \in{ }^{*} \lambda e^{\prime}\left(V\left(e^{\prime}\right) \wedge C\left(\theta\left(e^{\prime}\right)\right)\right) \wedge(C \neq \text { Atom } \rightarrow \bigoplus C=\theta(e))\right]
\end{aligned}
$$

As in the case of each, I assume that the free variable $\theta$ can be resolved through coindexation with a thematic relation. Unlike each, however, this is not required. In other cases to be discussed shortly, I will assume that it can also be resolved to other values such as $\tau$ (runtime) or id (the identity function). As for the free variable $C$, I assume that pragmatics ensures that it is either resolved to Atom or to a set whose elements are contextually familiar (see Schwarzschild 1996, Champollion 2016a). In the latter case, the second conjunct of (86) ensures that $C$ is an exact cover of $\theta(e)$, in the sense that the members of $C$ sum up exactly to $\theta(e)$ as opposed to some entity that properly contains $\theta(e)$; the point of this requirement will become clear at the end of this section. In the case of each, it was not necessary to state it because each only distributes over atoms in the first place. Atoms 
are stipulated to be exempt from this requirement because the set of atoms covers most of the domain of discourse.

The same type shift as in (83), modulo the exact-cover requirement, brings us from (86) to adnominal jeweils:

$$
\begin{aligned}
& \mathbb{\text { jeweils }}_{\theta, \mathrm{C}} \rrbracket_{\text {adnominal }} \\
& =\lambda P \lambda \Theta \lambda e[ \\
& \left.\quad \llbracket \operatorname{Part}_{\theta, \mathrm{C}} \rrbracket\left(\lambda e^{\prime}\left[P\left(\Theta\left(e^{\prime}\right)\right)\right]\right)(e) \wedge(C \neq \text { Atom } \rightarrow \bigoplus C=\theta(e))\right] \\
& =\lambda P \lambda \Theta \lambda e[ \\
& \left.\quad e \in{ }^{*} \lambda e^{\prime}\left[P\left(\Theta\left(e^{\prime}\right)\right) \wedge C\left(\theta\left(e^{\prime}\right)\right)\right] \wedge(C \neq \text { Atom } \rightarrow \bigoplus C=\theta(e))\right]
\end{aligned}
$$

In Section 4.4, we will encounter another instance of adnominal jeweils, whose meaning is identical to adverbial jeweils except that it distributes over individuals rather than events. One could easily unify it with (86) by treating its variables as untyped or type-polymorphic. More generally, it should be obvious that all these lexical entries have the same semantic common core. Still, they differ in their types and in the number and types of their arguments because they are formulated in a way that allows them to be used in syntax trees that correspond closely to the surface forms of sentences. This seems to me to be a reasonable tradeoff. For a related account, which makes the lexical entries of various distance-distributive items even more similar at the cost of adding more empty elements to the syntax, see LaTerza 2014a.

As in the case of the Part operator, the granularity parameter $C$ of jeweils can be set to Atom so long as its dimension parameter $\theta$ is set to a function into a count domain, such as agent. In that case, Part distributes over individuals and is equivalent to the D operator, as explained in Champollion 2016a. This accounts for the fact that when jeweils distributes over individuals, it is equivalent to each, as this German sentence illustrates:

Die Jungen haben jeweils agent,Atom zwei Affen gesehen.

The boys have DIST two monkeys seen

'The boys have each seen two monkeys.' = $(9)$

If - and only if - there is a supporting context, the anaphoric predicate $C$ can be set to a salient antecedent other than Atom. In that case, $\theta$ is free to adopt values with nonatomic ranges, such as $\tau$ (runtime). This leads to occasion readings. Suppose for example that (88) is uttered in a context where it is in the common ground that the boys have been to the zoo three times recently. The set that contains these three time intervals, call it zoovisit, is salient in 
Overt distributivity in algebraic event semantics

this context. The derivation proceeds along similar lines to what is shown in Figure 1 and yields the result shown in (89):

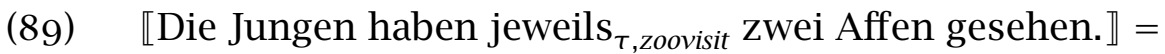
$\exists e\left[* \operatorname{agent}(e)=\bigoplus\right.$ boy $\wedge{ }^{*} \operatorname{see}(e)$

$$
\begin{aligned}
& \wedge e \in *^{*} \lambda e^{\prime}\left[\left.\right|^{*} \text { theme }\left(e^{\prime}\right) \mid\right.=2 \wedge{ }^{*} \operatorname{monkey}\left({ }^{*} \operatorname{theme}\left(e^{\prime}\right)\right) \\
&\left.\left.\wedge \operatorname{zoovisit}\left(\tau\left(e^{\prime}\right)\right)\right] \wedge \bigoplus \operatorname{zoovisit}=\boldsymbol{\tau}(e)\right]
\end{aligned}
$$

'The boys have seen two monkeys on each salient occasion (that is, on each of the three zoo visits).'

Since zoovisit is salient, $C$ can be resolved to it rather than to Atom. Since there are no atoms in time, it is only now that $\theta$ can be set to $\tau$, rather than to agent as in (88). What (89) asserts in this context is that there is an event $e$ whose (discontinuous) runtime is the sum of the three zoo visits; that this event has the boys as its agents; that it can be divided into subevents, each of whose runtimes is the time of a zoo visit; and that each of these subevents is an event whose theme is two monkeys. That these subevents are seeing events is entailed by the fact that see is lexically distributive on its theme argument, which in turn is formally represented as a meaning postulate, as discussed in Champollion 2016a. I assume that runtime is closed under sum just like other thematic roles $\left(\tau={ }^{*} \tau\right)$, or in other words, it is a sum homomorphism (Champollion 2016a). This means that any way of dividing $e$ must result in parts whose runtimes sum up to $\tau(e)$. The conjunct $\bigoplus$ zoovisit $=\tau(e)$ makes sure that $\tau(e)$ is the sum of the times of the three zoo visits in question. Hence each of these zoo visits must be the runtime of one of the seeing-two-monkeys events. This improves on an earlier version of this theory which lacked the conjunct in question (Champollion 2012). Without it, (89) would be predicted true even if the boys failed to see two monkeys on some of the salient zoo visits.

\section{Some more complicated cases}

To demonstrate the viability and versatility of the present analysis, I will now apply it to a few configurations that are more complicated than those discussed so far. The subsequent sections do not depend on this section. Detailed syntactic and semantic analyses of many of the configurations discussed here (and many others) are found in Zimmermann 2002b. Section 7 is devoted to a critical review of the semantic aspects of that account. 
Lucas Champollion

\subsection{Each as a PP modifier}

Each can occur as the modifier of a prepositional phrase. Example (90) is a simple case. Example (91) plays an important role in Schein 1993 and has not received a compositional semantic analysis so far.

(90) Mary put the books each back on the bookshelf. (Maling 1976)

(91) 300 quilt patches covered two workbenches each with two bed-spreads.

(Schein 1993)

To analyze these sentences, I assume that each modifies the prepositional phrase to its right, similarly to the adverb back in back at the farm, rather than the noun phrase to its left. (As (9o) shows, these modifiers can be stacked.) My assumption is plausible because adnominal each cannot modify definite plurals like the books. I assume for concreteness that the syntactic structure of these sentences is [[V DP] PP] rather than [V [DP PP]]; for discussion on the choice between these two analyses, see Janke \& Neeleman 2012.

Example (91) has a reading according to which there are a total of two workbenches and a total of four bedspreads that cover them. The workbenches stand in a cumulative relation with the 300 quilt patches. The following formula captures this reading:

(92) $\exists e .{ }^{*} \operatorname{cover}(e)$

$\wedge{ }^{*}$ quilt-patch $(*$ theme $(e)) \wedge \mid *$ theme $(e) \mid=300$

$\wedge{ }^{*}$ workbench $\left({ }^{*} \operatorname{goal}(e)\right) \wedge\left|{ }^{*} \operatorname{goal}(e)\right|=2$

$\wedge e \in{ }^{*} \lambda e^{\prime}\left[{ }^{*} \operatorname{bed} \operatorname{spread}\left({ }^{*} \operatorname{instrument}\left(e^{\prime}\right)\right)\right.$

$\left.\wedge\left|* \operatorname{instrument}\left(e^{\prime}\right)\right|=2 \wedge \operatorname{Atom}\left(\operatorname{goal}\left(e^{\prime}\right)\right)\right]$

(There is a sum of covering events whose themes sum up to 300 quilt patches, whose goals sum up to two workbenches, and which can be divided into two smaller sum events, each of which involves two bedspreads and one of the workbenches.)

Formula (92) is derived as follows. I have used shortcuts like 30o-quilt-patches for better readability. The derivation is straightforward and does not make use of any new ingredients. The entry for each is the same as the adverbial one, even though it modifies a prepositional phrase and not a verb phrase. This works because the prepositional phrase is represented as an event predicate, just like a verb phrase.

(93) $\llbracket \mathrm{each}_{\text {goal }} \rrbracket=\lambda V \lambda e . e \in^{*} \lambda e^{\prime}\left[V\left(e^{\prime}\right) \wedge \operatorname{Atom}\left(\operatorname{goal}\left(e^{\prime}\right)\right)\right]$ 
Overt distributivity in algebraic event semantics

(94) 【with two bedspreads $\rrbracket=\lambda e . t w o-b e d s p r e a d s(* \operatorname{instrument}(e))$

(95) «each goal $_{\text {with }}$ two bedspreads $\rrbracket$ $=\lambda e . e \in{ }^{*} \lambda e^{\prime}\left[\operatorname{two}-\operatorname{bedspreads}\left({ }^{*} \operatorname{instrument}\left(e^{\prime}\right)\right) \wedge \operatorname{Atom}\left(\operatorname{goal}\left(e^{\prime}\right)\right)\right]$

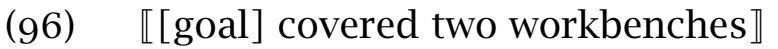
$=\lambda e \cdot{ }^{*} \operatorname{cover}(e) \wedge$ two-workbenches $\left({ }^{*} \operatorname{goal}(e)\right)$

(97) $\llbracket[$ theme $] 300$ quilt patches $\rrbracket=\lambda e$.300-quilt-patches $(*$ theme $(e))$

(98) $\llbracket(91) \rrbracket=\exists e . e \in(97) \cap(96) \cap(95)=(92)$

\subsection{Jeweils distributing over a conjunction of verbs}

German jeweils can take a conjunction of verbs as its antecedent and distribute over the two events described by the conjuncts (Moltmann 1997: 207). This results in a meaning for which English uses the word respectively:

(99) Peter kritisierte und lobte Maria aus jeweils zwei Gründen. Peter criticized and praised Mary for DIST two reasons 'Peter criticized and praised Mary for two reasons respectively.' (Zimmermann 2002b: 46)

As for English each, it cannot be used for that purpose:

(100) *Peter criticized and praised Mary for two reasons each.

(Zimmermann 2002b: 134)

According to Zimmermann (2002b: 143f.), other languages that pattern with English in this respect include Bulgarian, Czech, Dutch, French, Italian, Norwegian, and Russian. As we saw in Section 2, this list includes many languages with distance-distributive items that can also be used as determiners and lack the occasion reading. I have suggested earlier that the occasion reading is only possible if the granularity parameter can be set to a nonatomic value. Therefore, distributivity over conjuncts is predicted to be impossible as long as the events described by the two conjuncts are nonatomic (contrary to Zimmermann 2002a). There is ample reason to assume that they are indeed nonatomic. For one thing, praise and criticize are atelic predicates, so any praising event that goes on for five minutes will have parts that take less than five minutes. As another example, sentence (101) (suggested by a reviewer) entails that each of the six students was either praised or criticized, which means that the two verbs are lexically distributive on their themes (Champol- 
lion 2016a). This in turn means that the praising event in (101) consists of three praising subevents, and similarly for the criticizing event.

(101) Der Professor hat jeweils drei Studenten gelobt und kritisiert. The professor has DisT three students praised and criticized 'The professor praised three students and criticized three students.'

(German)

This explanation will work for most of the languages just mentioned, but not for all of them. As we saw in Section 2, in Bulgarian and Czech the distance-distributive item po can be used to distribute over salient occasions and cannot be used as a distributive determiner. We would therefore expect that this item allows distribution over conjuncts, but it does not. Like Zimmermann, I have no explanation for this fact.

To derive (99) compositionally, I assume that the dimension parameter $\theta$ of jeweils is resolved to the identity function $i d$ rather than to a thematic role. As jeweils is not syntactically required to be coindexed with a thematic role, it is natural to assume that there are other salient functions that are licit values to be picked up by its dimension parameter. I also assume that the cover variable $C$ is resolved to the pragmatically salient cover $\left\{e_{c}, e_{p}\right\}$ where $e_{c}$ is the salient criticizing-for-two-reasons event and $e_{p}$ is the salient praising-for-two-reasons event.

(102) «jeweils $s_{i d, C} \rrbracket_{\text {adnominal }}$ $=\lambda P \lambda \Theta \lambda e\left[e \in^{*}\left(P\left(\Theta\left(e^{\prime}\right)\right) \wedge C\left(e^{\prime}\right)\right) \wedge(C \neq\right.$ Atom $\left.\rightarrow \bigoplus C=e)\right]$

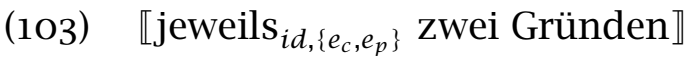
$=\lambda \Theta \lambda e . e \in{ }^{*} \lambda e^{\prime}\left[\right.$ 2-reasons $\left.\left(\Theta\left(e^{\prime}\right)\right) \wedge e^{\prime} \in\left\{e_{c}, e_{p}\right\}\right] \wedge e_{c} \oplus e_{p}=e$

I assume that aus (in this context) denotes a function from events to their causes (or whatever is the relation between a praising/criticizing event and its reason).

(104) $\llbracket$ aus $\rrbracket=\lambda e . * \operatorname{cause}(e)$

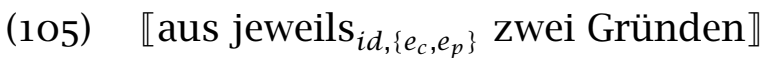
$=\lambda e . e \in{ }^{*} \lambda e^{\prime}\left[2\right.$-reasons $\left.\left({ }^{*} \operatorname{cause}\left(e^{\prime}\right)\right) \wedge e^{\prime} \in\left\{e_{c}, e_{p}\right\}\right] \wedge e_{c} \oplus e_{p}=e$

I represent the denotation of the verbal conjunction using sum formation as in (106). I remain noncommittal about the compositional derivation of this conjunction. For present purposes, we do not need to choose between 
Overt distributivity in algebraic event semantics

a sum-based denotation of and, as in Lasersohn 1995, and an intersective denotation that involves Montague-lifting the two event predicates and then minimizing their intersection, as in Winter 2001, Champollion 2015d, and Champollion 2016b.

(106) 【kritisierte und lobte $\rrbracket$

$$
=\lambda e \exists e_{1} \exists e_{2} \cdot{ }^{*} \operatorname{criticize}\left(e_{1}\right) \wedge{ }^{*} \text { praise }\left(e_{2}\right) \wedge e=e_{1} \oplus e_{2}
$$

Once all these building blocks have been put together and conjoined with the agent and theme, the result is as follows:

(107) $\llbracket(99) \rrbracket=\exists e$.agent $(e)=$ peter $\wedge$ theme $(e)=$ maria

$$
\begin{aligned}
& \wedge \exists e_{1} \exists e_{2}{ }^{*} \operatorname{criticize}\left(e_{1}\right) \wedge^{*} \text { praise }\left(e_{2}\right) \wedge e=e_{1} \oplus e_{2} \\
& \wedge e \in{ }^{*} \lambda e^{\prime}\left[2 \text {-reasons }\left({ }^{*} \operatorname{cause}\left(e^{\prime}\right)\right) \wedge e^{\prime} \in\left\{e_{c}, e_{p}\right\}\right] \\
& \wedge e_{c} \oplus e_{p}=e
\end{aligned}
$$

This is true just in case there is an event whose agent is Peter, whose theme is Maria, and which consists of two subevents $e_{c}$ and $e_{p}$ such that one of them is a criticizing event, the other one is a praising event, and each of these subevents is caused by two reasons. By thematic uniqueness, each of these two events has Peter as agent and Maria as theme.

\subsection{Jeweils in subject position}

As we have already seen in (8), German adnominal jeweils can occur as part of the subject of a clause (Zimmermann 2002b: 27):

(108) Jeweils ein Offizier begleitete die Ballerinen nach Hause. DisT one officer accompanied the ballerinas to home 'The ballerinas were accompanied home by one officer each.'

(Zimmermann 2002b)

When the subject is at the beginning of the clause, as in (8) and (108), one may speak of "backwards distributivity" since the antecedent of jeweils occurs to its right. In English, backwards distributivity appears to be restricted to passives (Burzio 1986, Safir \& Stowell 1988) and unaccusatives:

(109) *One officer each accompanied the ballerinas home.

(Zimmermann 2002b)

(110) ?One interpreter each was assigned to the visitors. (Burzio 1986: 200) 
(111) Table 3 shows the dissertation topics for those holding earned doctorates. [...] Three dissertations each dealt with assessment, transfer, trustees, and technical education. Two dissertations each were on accreditation, counseling, effectiveness, and mission. One dissertation each focused on economic development, learning resources, performing arts, and strategic planning..$^{51}$

(112) Indeed, Mr. Mitsotakis commanded only 144 seats [...] The Socialists won 125 seats $[\ldots]$ and one seat each went to a conservative independent and to an ethnic Turk from Thrace, near the Turkish border. $^{22}$

I do not have a semantic explanation for the restriction against backwards distributivity in English. As in the case of locality constraints, I assume that this restriction can be dealt with by syntactic accounts such as the ones already proposed, for example by Safir \& Stowell (1988). As one reviewer suggests, one might expect $\theta$-indexing to turn out to obey a hierarchy comparable to the hierarchies of thematic roles that are sometimes claimed to be at work in binding theory (Jackendoff 1972: 148, see also Büring 2005: 16). If correct, this may help explain why attested cases of inverse distribution in English, such as the ones we have seen in (111) and (112), tend to involve nonagent subjects.

For the German case, where there is no restriction, my account can easily be used to derive the meaning of (108) if we assume that the dimension parameter of jeweils is provided by the thematic role of die Ballerinen. Here are the core elements of the derivation; I assume that ein Offizier is interpreted predicatively. Here and below, I omit the exact-cover conjunct $(C \neq$ Atom $\rightarrow \oplus C=e)$ whenever it is vacuously true.

(113) 【jeweils theme,Atom $\rrbracket$ adnominal $=\lambda P \lambda \Theta \lambda e . e \in^{*} \lambda e^{\prime} . P\left(\Theta\left(e^{\prime}\right)\right) \wedge \operatorname{Atom}\left(\right.$ theme $\left.\left(e^{\prime}\right)\right)$

(114) «[agent] jeweils $s_{\text {theme,Atom }}$ ein Offizier $\rrbracket$ $=\lambda e . e \in^{*} \lambda e^{\prime}$.officer $\left(\operatorname{agent}\left(e^{\prime}\right)\right) \wedge \operatorname{Atom}\left(\right.$ theme $\left.\left(e^{\prime}\right)\right)$

(115) «begleitet [theme] die Ballerinen》 $=\lambda e{ }^{*} \operatorname{accompany}(e) \wedge{ }^{*}$ theme $(e)=\bigoplus$ ballerina

51 Attested example. Keim \& Murray 2008: 125f..

52 Attested example. New York Times, “Greek Conservative Is Seeking Coalition”, June 20, 1989. 
Overt distributivity in algebraic event semantics

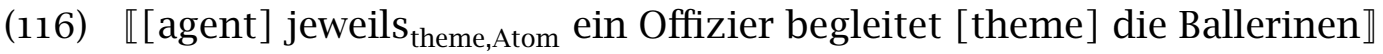
$=\exists e{ }^{*} \operatorname{accompany}(e) \wedge{ }^{*}$ theme $(e)=\bigoplus$ ballerina

$\wedge e \in{ }^{*} \lambda e^{\prime}$.officer $\left(\operatorname{agent}\left(e^{\prime}\right)\right) \wedge \operatorname{Atom}\left(\operatorname{theme}\left(e^{\prime}\right)\right)$

What (116) says is that there is a sum of accompanying events whose themes sum up to the ballerinas and which consists of parts $e^{\prime}$ such that each $e^{\prime}$ has an atomic theme and an officer as its agent.

These are the correct truth conditions for the German sentence (108). But given that its English counterpart (109) is ruled out, why is (108) acceptable? This question needs to be answered by a syntactic theory, and I can only offer speculation. One possible explanation is that there are language-specific constraints on $\theta$-indexing. This is consistent with the fact that even in German, there appears to be a clausemate requirement between jeweils and its antecedent (Zimmermann 2002b: 26f.). Another possibility is that distancedistributive items differ across languages in whether they require $\theta$-indexing in order to distribute over another element in the sentence. (The clausemate requirement must then be due to something else than a formal link between jeweils and its antecedent. For example, it could be due to a requirement that they modify the same event.) On this view, jeweils in (108) is not actually coindexed with the $\theta$-role of the ballerinas. Rather, it distributes over a set of occasions which stand in a one-to-one relation with the ballerinas and which are made salient by the fact that the ballerinas are mentioned in the sentence. If this is correct, there is no formal link between jeweils and the ballerinas. This makes an interesting prediction: the languages that allow distance-distributive items in subject position should be just the ones that allow distribution over salient entities that need not be overtly mentioned and need not be atomic. This prediction indeed appears to be borne out (Zimmermann 2002b: 48-50): besides German, at least Bulgarian, Czech, Korean and Polish have distance-distributive items that can occur in subject position (for Polish, see Przepiórkowski 2013). Besides English, at least Dutch, French, Icelandic, Italian, Norwegian, and Russian have distance-distributive items that cannot occur in subject position (setting aside English passives and unaccusatives). We saw in Section 2 that distance-distributive items in the first set of languages allow distribution over salient nonatomic entities, while those in the second set do not. 
Lucas Champollion

\subsection{Reverse DP-internal distributivity}

The analysis can be extended to a configuration halfway between the adverbial and adnominal case: backwards distributivity within a noun phrase. I illustrate this case with a German example:

(117) Das Parlament hat jeweils zwei Abgeordnete aus den The parliament has DisT two representatives from the.ACC.PL drei baltischen Staaten eingeladen. three Baltic states invited 'From each of the three Baltic states, two representatives were invited by the parliament.'

(German)

A parallel construction is available with Polish distributive po; both in German and in Polish, this configuration poses a problem for the account in Zimmermann 2002b, as discussed in detail by Przepiórkowski (2014a, 2015). As I show here, the present account can be extended straightforwardly to this kind of configuration. For a semantic analysis in a different framework, see also Przepiórkowski 2014a,b.

I write $e s \oplus l a \oplus l i$ for the sum of the three Baltic states, Estonia, Latvia, and Lithuania. I assume that in this context, aus ('from') denotes a function that maps individuals to their origins, and that is closed under sum:

$$
\llbracket \operatorname{aus} \rrbracket=\lambda y \lambda x .^{*} \operatorname{origin}(x)=y
$$

The prepositional phrase then denotes the set of all plural individuals whose origins are the three Baltic states:

(119) $\llbracket$ aus den drei baltischen Staaten $\rrbracket=\lambda x . * \operatorname{origin}(x)=e s \oplus l a \oplus l i$

The complex noun phrase denotes a sum of six representatives consisting of three pairs, with each pair coming from one of the three Baltic states. Although this instance of jeweils is adnominal, it has the denotation of adverbial jeweils in (85) except that it ranges over individuals instead of events. In the sentence at hand, its dimension parameter is set to the origin function I used as the denotation of aus, and its granularity parameter to Atom (since each pair of representatives comes from a single Baltic state).

$$
\llbracket \text { jeweils }{ }_{\text {origin,Atom }} \rrbracket=\lambda P \lambda x . x \in{ }^{*} \lambda y . P(y) \wedge \operatorname{Atom}(\operatorname{origin}(y))
$$


Overt distributivity in algebraic event semantics

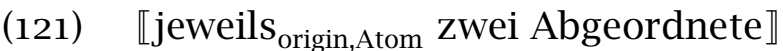

$=\lambda x \cdot x \in{ }^{*} \lambda y \cdot|y|=2 \wedge{ }^{*}$ representative $(y) \wedge \operatorname{Atom}(\operatorname{origin}(y))$

The denotation of the complex noun phrase is the intersection of (119) and (121). After it combines with the theme $\theta$-head via the type shifter in $(76 \mathrm{~b})$, the result is this:

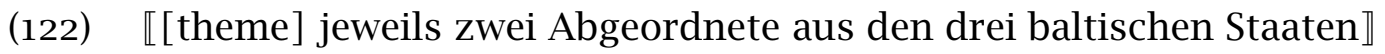

$=\lambda e .{ }^{*}$ origin $(*$ theme $(e))=e s \oplus l a \oplus l i \wedge$

$*$ theme $(e) \in{ }^{*} \lambda y .|y|=2 \wedge{ }^{*}$ representative $(y) \wedge \operatorname{Atom}(\operatorname{origin}(y))$

After combining with the main verb eingeladen and with the subject Das Parlament, the final result is as follows:

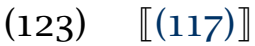

$=\exists e \cdot{ }^{*} \operatorname{agent}(e)=\iota x[\operatorname{parliament}(x)] \wedge$

$*$ invite $(e) \wedge{ }^{*} \operatorname{origin}(* \operatorname{theme}(e))=e s \oplus l a \oplus l i \wedge$

${ }^{*}$ theme $(e) \in{ }^{*} \lambda y .|y|=2 \wedge{ }^{*}$ representative $(y) \wedge \operatorname{Atom}(\operatorname{origin}(y))$

This says that there is an inviting event whose agent is the parliament, and whose theme has the following properties: its origins sum up to the three Baltic states, and it consists of sums of two representatives, each of which has a single country as its origin. These are the desired truth conditions.

The present analysis could no doubt be improved, for example by generalizing the dimension parameter from functions to relations so that its values are not restricted to thematic roles, functions like runtime, and functiondenoting prepositions like aus 'from'. This would further increase its empirical coverage. I have not done so because my goals here do not include accounting for every possible syntactic configuration in which distancedistributive items can be used.

While the analysis so far focused on adnominal and adverbial each and their counterparts across languages, it is possible to assimilate distributive determiners such as each and every to these items. I turn to them now.

\section{Distributive determiners}

As we have seen, English each along with some of its crosslinguistic relatives can be used adnominally, adverbially, and as a determiner. I have suggested that the synonymy of these uses should be captured, ideally by essentially identical lexical entries. Another distributive determiner in English is every. 
Lucas Champollion

As shown by their incompatibility with collective predicates, both every and each are distributive:

(124) \#Every/\#Each soldier surrounded the castle. (Kroch 1974: Chapter 5) Traditionally, the determiners every and each are analyzed in terms of universal quantification (e.g., Montague 1973):

(125) $\llbracket$ every boy $\rrbracket_{\text {traditional }}=\lambda P \forall x[\operatorname{boy}(x) \rightarrow P(x)]$

This style of analysis is especially useful when one is interested in comparing them with other determiners from the perspective of generalized quantifier theory (e.g., Barwise \& Cooper 1981). This paper, however, focuses on the parallels between determiner each and its adnominal and adverbial counterparts. Therefore, instead of the traditional approach I will reuse the analyses of adverbial and adnominal each that we have already encountered. Since the differences between each and every are not a core concern of this paper, I will adopt the same analysis for both determiners. This is not to deny that there are differences between them. To mention some examples, determiner each, unlike every, is not clause-bounded (Szabolcsi 2010: 107). It has a strong preference for taking wide scope over its environment, more so than every (e.g., Ioup 1975, Beghelli 1997, Beghelli \& Stowell 1997, Tunstall 1998). Relatedly, each appears to impose a differentiation requirement on its subevents (Tunstall 1998, Brasoveanu \& Dotlačil 2015, Thomas \& Sudo 2016):

(126) a. A helper dyed every shirt.

both scopal orders possible b. A helper dyed each shirt. inverse scope strongly preferred

(127) Jake photographed \{ every / \#each \} student in the class, but not individually.

Another difference is that each can but every cannot readily be used to quantify over a set having only two members:

(128) a. $\{$ \#Every one / Each $\}$ of the two ...

(Vendler 1967: 77)

b. Cromwell held a bible in $\{\#$ every / each $\}$ hand.

(Aldridge 1982: 218)

Conversely, a variety of environments tolerate every but not each:

(129) a. $\quad\{$ Every / ?Each $\}$ ten weeks, he visits Spain. (Aldridge 1982: 221) 
Overt distributivity in algebraic event semantics

b. It took $\{$ every / *each $\}$ boy to lift the piano.

(Beghelli \& Stowell 1997: 98)

c. Not $\{$ every / *each $\}$ boy ate an ice-cream cone.

(Beghelli \& Stowell 1997: 99)

d. Almost $\{$ every / *each \} student left the room. (Farkas 1997: §3)

Discussions of these and further differences between every and each can be found in Vendler 1967: 76-79, Hogg 1977: 135-139, Aldridge 1982: 217222, Tunstall 1998: §4, Beghelli 1997, and Beghelli \& Stowell 1997: 98-104. The latter two papers also contain a comprehensive syntactic proposal that addresses many of the facts above. Having surveyed the differences between each and every, I will set them aside and focus on their common core. The analysis I will adopt is closely related to those in Kratzer 2000, Ferreira 2005, and Thomas 2015, but it is more concise than these analyses and makes the connection to the $\mathrm{D}$ operator prominent:

(130) $\llbracket$ each $\rrbracket_{\text {determiner }}=\llbracket$ every $\rrbracket$

$$
\begin{aligned}
& =\lambda P \lambda \theta \lambda V \lambda e\left[\theta(e)=\bigoplus P \wedge \llbracket D_{\theta} \rrbracket(V)(e)\right] \\
& =\lambda P \lambda \theta \lambda V \lambda e\left[\theta(e)=\bigoplus P \wedge e \in{ }^{*} \lambda e^{\prime}\left[V\left(e^{\prime}\right) \wedge \operatorname{Atom}\left(\theta\left(e^{\prime}\right)\right)\right]\right]
\end{aligned}
$$

I assume that the determiner combines first with a nominal (of type $\langle e, t\rangle$ ) and then with a $\theta$-head. Unlike its adnominal and adverbial counterparts, determiner each is not coindexed with anything because it is not a distancedistributive item. The thematic relation is contributed by the $\theta$-head. The result has the modifier type $\langle v t, v t\rangle$ and is ready to combine with the verb phrase or other verbal projection $V$. A sample noun phrase denotation is shown in (131), and a sample sentence in (132).

(131) «[agent] every boy $\rrbracket$

$=\lambda V \lambda e\left[{ }^{*} \operatorname{agent}(e)=\bigoplus\right.$ boy $\left.\wedge e \in e^{*} \lambda e^{\prime}\left[V\left(e^{\prime}\right) \wedge \operatorname{Atom}\left(\operatorname{agent}\left(e^{\prime}\right)\right)\right]\right]$

(Takes an event predicate $V$ and returns a predicate that holds of any event $e$ whose agent is all the boys and which consists entirely of events that are in $V$ and whose agents are individual boys.)

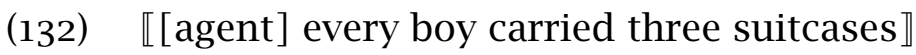

$$
=\exists e\left[* \operatorname { a g e n t } ( e ) = \bigoplus \text { boy } \wedge e \in { } ^ { * } \lambda e ^ { \prime } \left[{ }^{*} \operatorname{carry}\left(e^{\prime}\right) \wedge \operatorname{Atom}\left(\operatorname{agent}\left(e^{\prime}\right)\right) \wedge\right.\right.
$$

$\mid *$ theme $\left.\left.\left(e^{\prime}\right) \mid=3 \wedge{ }^{*} \operatorname{suitcase}\left(* \operatorname{theme}\left(e^{\prime}\right)\right)\right]\right]$

This says that there is an event $e$ whose agent is all the boys and which consists entirely of carrying events whose agents are individual boys and whose 
themes are sums of three suitcases. From this and from the assumption that the agent role is a sum homomorphism, we can conclude that every boy carried three suitcases.

Treating every and each as involving distributivity operators in a NeoDavidsonian event semantic framework like the present one avoids problems in connection with examples like the following (Taylor 1985, Schein 1993, Kratzer 2000, Ferreira 2005, Champollion 2010a, Thomas 2015):

(133) a. Unharmoniously, every organ student sustained a note on the Wurlitzer for sixteen measures.

(Schein 1993)

b. In a complete lack of harmony, each monk started to sing the Kyrie in a different mode.

(Thomas 2015)

The event modifiers in these examples need access to the sum of the events whose agents are the individuals quantified over by every and each. For reasons analogous to those discussed in Champollion 2016a in connection with leakage, the modified event must not be larger than that sum (Ferreira 2005: 23). The entry in (130) allows us to analyze (133a) correctly and concisely:

$$
\begin{aligned}
& \llbracket(133 a) \rrbracket=\exists e[\text { unharmonious }(e) \wedge * \operatorname{agent}(e)=\bigoplus \operatorname{organ} . s t u d e n t \wedge \\
& \left.e \in{ }^{*} \lambda e^{\prime}\left[* \operatorname{sustain}\left(e^{\prime}\right) \wedge \operatorname{note}\left(\operatorname{theme}\left(e^{\prime}\right)\right) \wedge \operatorname{Atom}\left(\operatorname{agent}\left(e^{\prime}\right)\right)\right]\right]
\end{aligned}
$$

(There is an unharmonious event $e$ whose agent is all the students and which consists entirely of note-sustaining events whose agents are individual students.)

Building on insights by Schein (1993) and Kratzer (2000), we can also use the sum event to account for cumulative readings of every and each such as the ones available in (135a) and (135b).

(135) a. Three video games taught every quarterback two new plays.

(Schein 1993)

b. Three copy editors caught every mistake (in the manuscript).

(Kratzer 2000)

c. Two farmers sold each sheep to one customer.

(Thomas \& Sudo 2016)

Such configurations cause problems for the traditional analysis in (125), which does not provide us with access to this sum event. Just as the adverbial modifier unharmoniously needs access to the sum of all the individual events in (133a), so do the subject noun phrases in (135). For example, the cumulative 
Overt distributivity in algebraic event semantics

reading of (135b) can be paraphrased roughly as 'There is a sum of mistakecatching events, whose agents sum up to three copy editors, and every mistake was caught in at least one of these events' (Schein 1993, Kratzer 2000, Champollion 2010a). In this reading, the relationship between the two verbal arguments is cumulative and symmetric. There is no entailment that any mistake was caught by more than one copy editor, as would be expected if every mistake took scope either above or below three copy editors. My analysis of this reading is as follows.

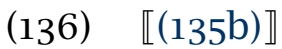

$=\exists e\left[|* \operatorname{agent}(e)|=3 \wedge{ }^{*} \operatorname{copy}\right.$-editor $(* \operatorname{agent}(e)) \wedge$

${ }^{*}$ theme $(e)=\bigoplus$ mistake $\left.\wedge e \in{ }^{*} \lambda e^{\prime}\left[{ }^{*} \operatorname{catch}\left(e^{\prime}\right) \wedge \operatorname{Atom}\left(\operatorname{theme}\left(e^{\prime}\right)\right)\right]\right]$

This formula says that there is an event whose agents sum up to three copy editors, whose themes sum up to all the mistakes, and which consists of catching events with atomic themes. That these themes are individual mistakes follows from cumulativity of thematic roles.

It appears that every can never enter a cumulative relation with an argument in its syntactic scope (Champollion 2010a). For example, (137) does not have a cumulative reading, in contrast to (135b) (Kratzer 2000).

(137) Every copy editor caught 500 mistakes.

Likewise, Bayer (1997) judges (138a) to be “clearly bizarre" because scripts cannot be written more than once, but reports that (138b) has a reading where every screenwriter in Hollywood contributed to the writing of the movie.

(138) a. Every screenwriter in Hollywood wrote Gone with the Wind.

b. Gone with the Wind was written by every screenwriter in Hollywood.

Assuming that Gone with the Wind denotes a sum entity, we can represent (138b) as a cumulative reading. Similarly, Zweig (2008) reports that (139a) entails that each game was won by both teams at once, but (139b) has a cumulative reading, in which either team won games and every game was won by only one of the teams.

(139) a. Every game was won by the Fijians and the Peruvians.

b. The Fijians and the Peruvians won every game. 
These facts are in line with what we would expect, since every distributes over its syntactic scope but makes the sum event available for arguments or adverbs further up the tree. In (138a) and (139a), the syntactic scope of the argument headed by every is the entire verb phrase. The verb phrase includes the other argument, which is then related as a whole to each of the individual screenwriters or games. As a result, the every-phrase takes scope over its coargument and a cumulative reading is ruled out.

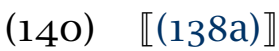

$=\exists e\left[{ }^{*} \operatorname{agent}(e)=\bigoplus\right.$ screenwriter

$$
\wedge e \in{ }^{*} \lambda e^{\prime}\left[{ }^{*} \operatorname{write}\left(e^{\prime}\right) \wedge \operatorname{Atom}\left(\operatorname{agent}\left(e^{\prime}\right)\right)\right.
$$

$\wedge *^{*}$ theme $\left(e^{\prime}\right)=\llbracket$ Gone with the Wind $\left.\left.\rrbracket\right]\right]$

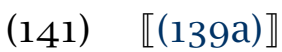

$=\exists e\left[{ }^{*}\right.$ theme $(e)=\bigoplus$ game

$\wedge e \in{ }^{*} \lambda e^{\prime}\left[{ }^{*} \operatorname{win}\left(e^{\prime}\right) \wedge \operatorname{Atom}\left(\operatorname{theme}\left(e^{\prime}\right)\right)\right.$

$\wedge{ }^{*}$ agent $\left(e^{\prime}\right)=\llbracket$ the Fijians and the Peruvians $\left.\left.\rrbracket\right]\right]$

By contrast, in (138b) and (139b), the syntactic scope of the every-phrase only includes the verb. For this reason, it does not distribute over the other argument, and a cumulative reading is possible. Distributing over the verb does not amount to anything much in (139b) since win is already distributive on its theme.

$(142) \llbracket(138 b) \rrbracket$

$=\exists e\left[{ }^{*}\right.$ theme $(e)=\llbracket$ Gone with the Wind $\rrbracket$ $\wedge *$ agent $(e)=\bigoplus$ screenwriter

$\left.\wedge e \in{ }^{*} \lambda e^{\prime}\left[{ }^{*} \operatorname{write}\left(e^{\prime}\right) \wedge \operatorname{Atom}\left(\operatorname{agent}\left(e^{\prime}\right)\right)\right]\right]$

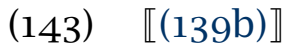

$=\exists e[$ *agent $(e)=\llbracket$ the Fijians and the Peruvians $\rrbracket \wedge$

${ }^{*}$ theme $(e)=\bigoplus$ game $\wedge e \in{ }^{*} \lambda e^{\prime}\left[{ }^{*} \operatorname{win}\left(e^{\prime}\right) \wedge \operatorname{Atom}\left(\right.\right.$ theme $\left.\left.\left.\left(e^{\prime}\right)\right)\right]\right]$

Kratzer 2000 claims that the availability of cumulative readings depends on the thematic role of the coargument of the every-phrase. According to her, cumulativity is only possible when the coargument plays the agent role. However, (138b), where the role of the coargument is theme, is a counterexample (Champollion 2010a).

The entry for each/every in (130) can be refined in various ways. For example, the subformula $\theta(e)=\bigoplus P$ could be replaced by a contextually supplied variable that specifies the domain of quantification (see e.g., Stanley 
Overt distributivity in algebraic event semantics

\& Szabó 2000, Schwarz 2009). This variable could be made dependent on another universal quantifier or on a temporal modifier:

(144) a. Every child ate every apple.

(Farkas 1997)

b. John found a flea on his dog every day for a month.

(Zucchi \& White 2001)

In order to keep the system simple, I will refrain from adding these refinements here. The temporal case, every day, is discussed in Champollion 2016a.

A related issue is how to analyze the expression every/each time. Although I have used it to paraphrase occasion readings of distance-distributive items like jeweils, we cannot reuse the analysis of those readings. While I have argued that occasion readings involve a nonatomic setting of the granularity parameter, in the case of each time this is not a plausible option. It is natural to assume that expressions involving each and mass nouns, like *each mud or *each silverware, are ruled out by the atomicity requirement of each, which I have implemented by setting its granularity parameter to Atom. Since all count nouns are compatible with each, even those with unclear individuation criteria such as twig or fence, it follows that they are all atomic (Rothstein 2010). The same reasoning applies to the entities in the denotation of time, which is not a mass noun either. On the relevant sense, then, time is a nontemporal expression which parcels noncountable entities into countable atoms (Landman 2004: Chapters 10-11). This sense is particularly vivid in sentences like (145):

(145) Each time the bell rings, Mary opens the door.

Such sentences have been analyzed as involving a one-to-one "matching function", in this case from door openings to bell ringings (Rothstein 1995). On this view, (145) means that every bell-ringing event is the "match" of a different door-opening by Mary. Assuming that the matching function is a sum homomorphism, this type of analysis can be implemented within the present system. Here is the core piece of the derivation:

(146) $\llbracket$ each time the bell rings $\rrbracket=$ $\lambda V \lambda e{ }^{*} \operatorname{match}(e)=\bigoplus \llbracket$ time the bell rings $\rrbracket \wedge$

$$
e \in{ }^{*} \lambda e^{\prime} . V\left(e^{\prime}\right) \wedge \operatorname{Atom}\left({ }^{*} \operatorname{match}\left(e^{\prime}\right)\right)
$$


For a detailed analysis of this construction, see Landman 2004: Chapters 1011. That analysis can also be applied to sentences like (147):

(147) When the bell rings, Mary opens one door each time.

A related question is why the when-clause that licenses each time in (147) cannot license adnominal each in (148):

(148) *When the bell rings, Mary opens one door each.

This is a surprising fact. If door involves a one-to-one matching function from door openings to "times the bell rings", one expects (147) to involve it as well. This matching function has been argued to be a $\theta$-role that is introduced by a silent preposition (Rothstein 1995). If so, the dimension parameter of adnominal each in (148) should be able to acquire this matching function as its value via $\theta$-indexing. Setting the granularity parameter to Atom should also be possible since the entities in the denotation of time are atomic; otherwise, each time would be ungrammatical.

Why, then, is (148) ungrammatical? One possible explanation is that $\theta$-indexing of English adnominal each is only available for $\theta$-roles that correspond to (silent or overt) prepositions. Landman (2004: Chapter 10) argues contra Rothstein 1995 that sentences like (145) do not involve silent prepositions, and that the matching function expressed by these sentences is not a $\theta$-role but a measure function.

We can also explain why (147), in which the word time is present, is grammatical. In this case, the word each is not adnominal but a determiner. Since determiner each is not distance-distributive, it does not need to be $\theta$-indexed with anything. Therefore the absence of a relevant $\theta$-role does not lead to a violation. The sentence can then be analyzed as in Landman 2004.

Now that we have extended the analysis of distance-distributive items to the English determiners every and each, we are in a position to explain the generalization discussed in Section 2 concerning distance-distributive items and determiners across languages.

\section{Zimmermann's generalization explained}

How can we capture the correlation expressed in Zimmermann's generalization (17)? That is to say, why does a distance-distributive item which can also be used as a distributive determiner lack the occasion reading? One 
Overt distributivity in algebraic event semantics

possible explanation is syntactic, as proposed in Zimmermann 2002b. Determiners must agree with their complement; adnominal or adverbial each also has a complement, a proform that must acquire its agreement features from its antecedent, which is the antecedent of each; only overt antecedents have agreement features; so adnominal/adverbial each cannot have a covert antecedent; so it cannot refer to a contextually supplied but not overtly mentioned antecedent such as a salient set of occasions.

This explanation is compatible with the present framework, and it makes the right predictions given the assumption that covert antecedents cannot trigger agreement. However, this assumption is problematic. To mention a simple example, German has grammatical gender. The gender of Tisch 'table' is masculine. Knowing this, a German speaker can point to a table and say with reference to it:

(149) Den hab ich gebraucht gekauft.

This.ACC.M have I used bought

'I have bought this used.'

(German)

But the same speaker cannot point to it and say:

(150) *Die hab ich gebraucht gekauft.

This.ACC.F have I used bought

Intended: 'I have bought this used.'

(German)

As this example shows, a deictic pronoun in German has to agree in grammatical gender with the gender of the noun phrase that would most aptly describe this antecedent, even though this noun phrase has not been mentioned explicitly.

A similar phenomenon was pointed out for English by Tasmowski-De Ryck \& Verluyten (1982). English pronouns agree with their antecedents based on syntactic rather than semantic grounds, as is shown by pluralia tantum such as pants and scissors which are syntactically plural but semantically singular. Pronouns show syntactic agreement with their antecedents even when these antecedents are not overtly mentioned:

(151) a. (John wants his pants that are on a chair and he says to Mary:)

Could you hand them/*it to me, please?

b. (Same situation but with a shirt:)

Could you hand *them/it to me, please? 
For a recent discussion of these facts, and an explanation in terms of covert syntactic antecedents that are included in the syntactic structure and ccommand the entire sentence in question, see Collins \& Postal 2012: Chapter 4 . In the following I will remain neutral on whether the covert syntactic antecedent should be thought of as being included in the syntactic structure or not.

While Zimmermann's explanation of his generalization seems problematic, its difficulties can perhaps be overcome, and it is by itself not incompatible with the present framework. But in the context of the general theory adopted here, a more straightforward explanation suggests itself. The atomicity requirement of English each is of the same kind that Link's D operator provides, as discussed in Champollion 2016a. The motivation for this requirement, discussed in Section 5, can be seen as independent evidence of the atomic distributivity hard-coded in the entry (130) via the D operator. In other words, the distance-distributive item inherits the atomicity requirement of the determiner. This explanation is in line with the notion of parameter settings imported from strata theory as described above. That is, in English, adnominal, adverbial and determiner each have essentially identical meanings. Determiner each is only compatible with count domains because its granularity parameter is hardwired to the value Atom. Adnominal each is formally identical to determiner each, so it inherits this property.

The German distributive determiner that corresponds to each and every is jeder. The distance-distributive item jeweils cannot be used in this position. This is illustrated in sentence $(7 \mathrm{c})$, repeated here:

(152) Jeder/*Jeweils Junge hat drei Koffer getragen. DIST.SG.M/DIST boy has three suitcases carried 'Every boy has carried three suitcases.'

(German)

This determiner can in turn also be used as an adverbial distance-distributive item. Like English each, and unlike German jeweils, it can only distribute over individuals, but not over salient occasions.

(153) Die Jungen haben jeder zweimal geniest. The boys have DIST.SG.M twice sneezed Available: 'The boys have each twice sneezed.' Unavailable: 'The boys have sneezed twice on each occasion.'

(154) *Hans hat jeder zweimal geniest. Hans has DisT.SG.M twice sneezed 
Overt distributivity in algebraic event semantics

Intended: 'Hans has sneezed twice on each occasion.'

As we see here, the distance-distributive item jeder can also be used as a distributive determiner, and it lacks the occasion reading. The distancedistributive item jeweils cannot be used as a distributive determiner, and as we have seen before, it has the occasion reading. All this is in line with Zimmermann's generalization. We can account for it by assuming that jeder, like each, corresponds to the D operator (its granularity parameter can only be Atom), while jeweils corresponds to the Part operator (its granularity can be set to a nonatomic predicate if it is contextually salient). Concretely, I propose the following denotations for adverbial and determiner jeder. They are identical with adverbial and determiner each respectively. As for jeweils, we have already seen its entry in (86).

(155) $\llbracket$ jeder $_{\theta} \rrbracket_{\text {adverbial }}=\llbracket$ each $_{\theta} \rrbracket_{\text {adverbial }}=\llbracket \mathrm{D}_{\theta} \rrbracket \quad=(80)$

(156) $\llbracket$ jeder $\rrbracket_{\text {determiner }}=\llbracket$ every $\rrbracket$

$=\lambda P \lambda \theta \lambda V \lambda e\left[\theta(e)=\bigoplus P \wedge e \in{ }^{*} \lambda e^{\prime}\left[V\left(e^{\prime}\right) \wedge \operatorname{Atom}\left(\theta\left(e^{\prime}\right)\right)\right]\right]=(130)$

The derivation of (152) is exactly analogous to (132). Let me show a derivation of (153). For convenience, and to avoid getting into the difficult question of how to count events, I represent zweimal 'twice' as an unanalyzed intersective predicate of sum events. A more sophisticated analysis is found in Landman 2004: Chapters 10-11.

(157) $\llbracket$ [agent $]$ Die Jungen $\rrbracket=\lambda e[* \operatorname{agent}(e)=\bigoplus$ boy $] \quad=(77)$

(158) $\llbracket$ zweimal geniest $\rrbracket=\lambda e\left[\operatorname{twice}(e) \wedge{ }^{*} \operatorname{sneeze}(e)\right]$

(159) $\llbracket$ jeder ${ }_{\text {agent }}$ Zweimal geniest $\rrbracket=(156)((158))$

$=\lambda e\left[e \in{ }^{*} \lambda e^{\prime}\left(\operatorname{twice}\left(e^{\prime}\right) \wedge{ }^{*} \operatorname{sneeze}\left(e^{\prime}\right) \wedge \operatorname{Atom}\left(\operatorname{agent}\left(e^{\prime}\right)\right)\right)\right]$

(160) $\llbracket(153) \rrbracket=\exists e . e \in(157) \cap(159)$

$=\exists e\left[* \operatorname{agent}(e)=\bigoplus\right.$ boy $\wedge e \in{ }^{*} \lambda e^{\prime}\left(\operatorname{twice}\left(e^{\prime}\right) \wedge{ }^{*} \operatorname{sneeze}\left(e^{\prime}\right)\right.$

$\left.\left.\wedge \operatorname{Atom}\left(\operatorname{agent}\left(e^{\prime}\right)\right)\right)\right]$

This says that there is a sum event whose agents sum up to the boys, and which consists of sneezing-twice events with atomic agents.

As a reviewer notes, jeweils and jeder are morphologically related. They are both built around the distributive item je, which also functions as an adnominal distance-distributive item (Link 1998b, Zimmermann 2002b). On the present account, the underlying semantics of jeder and jeweils is related 
via the common core of the $\mathrm{D}$ and Part operators, discussed in Champollion 2016a. An interesting question is whether we can explain that the two of them denote related but different distributivity operators. A starting point might be the observation that the morpheme weil in jeweils is related to the noun Weile 'timespan, while'. However, the reviewer notes that the morpheme $j e$ is also found in words with quite distinct meanings, such as nie 'never', jeglich 'any kind', and je ... desto 'the ... the' (as in the bigger the better). As we can see, a common morphological core does not necessarily imply identical meanings. On these questions see also Zimmermann 2002b, who argues that weil is a proform; in terms of the present account, it might be the part of jeweils that is anaphoric on the variable $C$.

Having seen how Zimmermann's account of his generalization differs from the present one, it is time for a broader comparison of the two systems.

\section{Previous work: Zimmermann 2002b}

The most detailed semantic account of jeweils and each is offered in Zimmermann 2002b. I summarize and review it here. Other descriptions and critical discussions are found in Blaheta 2003, Dotlačil 2012, and Przepiórkowski 2015. My criticism of Zimmermann's integrated syntactic and semantic account is limited to its semantic component. I do not take issue with its syntactic component.

Zimmermann takes adnominal each and jeweils to be prepositional phrases that are only partially pronounced, but this aspect does not really influence the semantic composition. The meaning of each, or more precisely of the prepositional phrase that is supposed to contain it, is as follows (Zimmermann 2002b: 210). While the relevant discussion is actually about adnominal jeweils, it carries over to adnominal each without changes, so I present it in terms of each for clarity.

(161) $\llbracket \operatorname{each}_{i, j} \rrbracket($ Zimmermann)

$$
=\lambda P . \forall z\left[z \in Z_{i} \rightarrow \exists x\left[P(x) \wedge{ }^{*} R_{j}(z, x)\right]\right]
$$

This meaning is a property of predicates that holds of a given predicate $P$ if and only if every member of a certain plurality $Z_{i}$ stands in the pointwise algebraic closure ${ }^{*} R_{j}$ of a certain relation $R_{j}$ to some entity of which $P$ holds. In this definition, $Z_{i}$ and $R_{j}$ are free variables that are assumed to be coindexed, respectively, with the antecedent of each and with the relation that holds between the host phrase of each and its antecedent. That relation 
Overt distributivity in algebraic event semantics

is typically denoted by the verb. Take sentence (14), repeated here as (162) with the coindexation added. Here $P$ is the denotation of two monkeys, $Z$ is coindexed with the boys, and $R$ is coindexed with saw.

(162) [The boys $]_{i}$ saw $_{j}$ two monkeys each $_{i, j}$.

Here is how this sentence would be analyzed by Zimmermann 2002b. First, the entry for each is applied to two monkeys, which is taken to denote a predicate of sum individuals that I will represent here by the shorthand two-monkeys. This results in an open proposition with two free variables:

(163) «two monkeys each et,j $_{i, j}$

$$
=\forall z\left[z \in Z_{i} \rightarrow \exists x\left[\text { two-monkeys }(x) \wedge{ }^{*} R_{j}(z, x)\right]\right]
$$

The next steps involve $\lambda$-abstracting over the free variables, via a rule that Zimmermann calls "index-triggered $\lambda$-abstraction", a variant of a rule which has been proposed for configurations when a type mismatch makes function application impossible (Bittner 1994: 69).

(164) Index-triggered $\lambda$-abstraction (Zimmermann 2002b: 217):

If the semantic types of a proposition-denoting expression $\alpha$ and its syntactic sister $\beta$ do not match, and if $\llbracket \alpha \rrbracket$ contains a free variable $u_{i}$ that shares an index ' $\mathrm{i}$ ' with $\beta, \lambda$-abstraction in $\llbracket \alpha \rrbracket$ over index ' $\mathrm{i}$ ' is licensed, and $\lambda u_{i} \llbracket \alpha \rrbracket$ is a value for $\alpha$.

This rule allows a constituent with a free variable in it to combine with another constituent that is coindexed with that variable. For example, in (162), the constituent two monkeys each ${ }_{i, j}$ has the free variable $j$ in it, which carries the same index as the constituent $s a w_{j}$. (The need to identify free variables inside constituent denotations poses a challenge for compositionality. To overcome it, Zimmermann (2002a: 336) suggests using partial assignment functions.) Since the two constituents are sisters, index-triggered $\lambda$-abstraction applies, with the result as shown in (165), as discussed in Zimmermann 2002b: 226.

(165) $\lambda R_{j} . \forall z\left[z \in Z_{i} \rightarrow \exists x\left[\operatorname{two}-\operatorname{monkeys}(x) \wedge{ }^{*} R_{j}(z, x)\right]\right]$

Zimmermann takes the classical Davidsonian view on verb meaning, under which $n$-ary verbs denote $n+1$-ary relations between arguments and events. He tentatively proposes that the event argument can "at least sometimes" (p. 226) be saturated inside the verb phrase by existential closure. This means 
that the verb saw can have the right type to combine with (165), as shown below in the derivation taken from Zimmermann 2002b: 227:

(166) $\llbracket \operatorname{saw}_{j} \rrbracket=\lambda y \lambda x . \exists e[\operatorname{see}(x, y, e)]$

(167) $\llbracket(165) \rrbracket(\llbracket(166) \rrbracket)$

$$
=\forall z\left[z \in Z_{i} \rightarrow \exists x\left[\text { two-monkeys }(x) \wedge \exists e\left[{ }^{*} \operatorname{see}(z, x, e)\right]\right]\right]
$$

The result of the computation, in (167), is another open proposition. The last step in the derivation is to combine this with the antecedent, the boys $s_{i}$, in another instance of index-triggered $\lambda$-abstraction. The result is as follows:

$$
\forall z[(z \in \oplus \text { boy }) \rightarrow \exists x[\text { two-monkeys }(x) \wedge \exists e[* \operatorname{see}(z, x, e)]]]
$$

This formula says that for every boy there exists a sum of two monkeys such that the boy saw the monkeys. This is an accurate rendering of the truth conditions of sentence (162).

In Zimmermann's system, the denotation of the host phrase of adnominal each, given in (163), is of type $t$. This means that the only way it can combine with other constituents is via index-triggered $\lambda$-abstraction. The only two indices that can trigger this operation are the ones on $Z$ and $R$. The values for these two variables will therefore always be provided by the two constituents which are closest to the host phrase. Put another way, Zimmermann's system requires the host phrase of adnominal each to be adjacent either to its antecedent or to the constituent that denotes the relation between the two. Whatever intervenes between the host phrase of each and its antecedent will give its value to $R$.

Zimmermann (2002b: 24of.) justifies this adjacency requirement by noting that jeweils cannot distribute over individual-denoting noun phrases in a higher clause:

(169) *Die Verkäufer ${ }_{i}$ sagen, dass Peter jeweils $s_{i}$ einen Ballon gekauft hat. the store.clerks say, that Peter DIST a balloon bought has Intended: 'Each store clerk said that Peter had bought a balloon.' (Literally: “The store clerks said that Peter had bought a balloon each.')

(Zimmermann 2002b: 241)

As discussed earlier, this clausemate condition can also be explained by other means. As long as this locality constraint is sufficiently stringent, there is no need for an additional semantic adjacency requirement on top of it. Regardless of how the clausemate condition is implemented, Zimmermann's 
Overt distributivity in algebraic event semantics

adjacency requirement is not only redundant in those cases where it agrees with it, it is also too strong where it goes further. This is arguably the case in example (170) (Blaheta 2003: 42):

(170) Alex and Sasha lifted a piano with two jacks each.

In (170), it is possible that only one piano was lifted in a collective event. As Blaheta puts it, the phrase with two jacks each "needs to distribute itself in some fashion over each member of the subject, without making the verb phrase itself distribute!" Since the host phrase of each is not adjacent to its antecedent, it is not obvious how to analyze this configuration in Zimmermann's system. Blaheta leaves (170) as an open problem for his own account as well, which is closely related to Zimmermann's, and he conjectures that event semantics may hold the key to the solution.

This conjecture is correct. The compositional derivation of (170) is similar to the one in Section (91), except that each is $\theta$-indexed with the role of the subject, skipping the direct object:

(171) 【each agent $\rrbracket=\lambda V \lambda e . e \in{ }^{*} \lambda e^{\prime}\left[V\left(e^{\prime}\right) \wedge \operatorname{Atom}\left(\operatorname{agent}\left(e^{\prime}\right)\right)\right]$

(172) 【with two jacks $\rrbracket=\lambda e . t w o-j a c k s(* \operatorname{instrument}(e))$

(173) 【with two jacks each ${ }_{\text {agent }} \rrbracket$

$=\lambda e . e \in^{*} \lambda e^{\prime}\left[\operatorname{two}\right.$-jacks $\left.\left({ }^{*} \operatorname{instrument}\left(e^{\prime}\right)\right) \wedge \operatorname{Atom}\left(\operatorname{agent}\left(e^{\prime}\right)\right)\right]$

(174) $\llbracket[$ theme $]$ lifted a piano $\rrbracket$

$=\lambda e \cdot{ }^{*} \operatorname{lift}(e) \wedge$ piano $($ theme $(e))$

(175) $\llbracket[$ agent $]$ Alex and Sasha $\rrbracket=\lambda e$ * $^{*} \operatorname{agent}(e)=\operatorname{alex} \oplus$ sasha

$(176) \quad \llbracket(170) \rrbracket=\exists e . e \in(175) \cap(174) \cap(173)$

$=\exists e\left[* \operatorname{agent}(e)=\operatorname{alex} \oplus \operatorname{sasha} \wedge{ }^{*} \operatorname{lift}(e) \wedge \operatorname{piano}(\right.$ theme $(e))$

$\wedge e \in{ }^{*} \lambda e^{\prime}\left[\operatorname{two}\right.$-jacks $\left.\left.\left(* \operatorname{instrument}\left(e^{\prime}\right)\right) \wedge \operatorname{Atom}\left(\operatorname{agent}\left(e^{\prime}\right)\right)\right]\right]$

This formula entails that Alex and Sasha together lifted a piano, and that each of them was the agent of a part of the lifting event which had two jacks as its instrument. It does not entail that the parts of the lifting events need to be lifting events themselves. This is as it should be, because lift is not distributive on its agent position.

Schwarzschild (2014) points out a potential problem for the line of analysis developed here. Suppose that a group of artists build a wall of books on the sidewalk, with each artist putting one book down next to or on top of other books until a wall is built. In this scenario, each artist did something 
to one book. If we assume that all these events sum up to a building event, sentence (177) should be acceptable and true.

(177) \#The artists built one book each.

The deviant status of (177) can be explained by assuming that the building event is not in fact the sum of the individual events in which artists put down books. For discussion of an analogous problem involving the collective planting of a rosebush, see Kratzer 2007, A. Williams 2009 and Champollion $2010 b$. An alternative line of analysis would be to assume that in some cases including (177), the scope of adnominal each includes the verb phrase after all. This would raise the question how to delineate the cases in which adnominal each does and does not take scope over the verb phrase. I have not adopted this analysis because I do not see an easy way to answer this question.

\section{Summary and discussion}

I have suggested the following requirements for a theory of distributivity. First, the synonymy of the adverbial, adnominal, and determiner uses of each in English should be captured, ideally by essentially identical lexical entries. Second, the fact that distance-distributive items across languages share some part of their meanings (namely their individual-distributive readings) should be represented, as well as the fact that some of them can also have occasion readings in suitable contexts. Third, the analysis should clarify the connections between distance-distributive items and distributivity theory more generally, and it should capture the semantic variation across distancedistributive items. Finally, an explanation should be readily available for the crosslinguistic observation that distance-distributive items that can also be used as determiners can only distribute over individuals (Zimmermann's generalization).

I have addressed these issues in the following way. Distance-distributive items across languages are in essence overt versions of Link's D and Schwarzschild's Part operators. The synonymy of the determiner, adnominal and adverbial uses of each in English is captured by the fact that they are all derived from the D operator. I have represented the fact that distance-distributive items across languages share some part of their meanings by deriving them from related distributivity operators (Link's or Schwarzschild's), which differ from each other in their parameter settings and whether they require a formal link to their antecedents. On the theory presented here, distance-distributive 
items display the same parametric variation as covert distributivity operators do, not only insofar as nonatomic distributivity is concerned, but also insofar as the ability is concerned to target different thematic roles or time. While the syntactic variation among distance-distributive items is due to constraints on formal links that the present theory does not aim to capture, the semantic variation is captured by restrictions on parameter settings. One type of element, exemplified by English each, is hardwired for distribution over atoms; the other one, exemplified by German jeweils, also allows distribution over nonatomic contexts. Zimmermann's generalization is explained by the natural assumption that distance-distributive items are formally identical to distributive determiners and therefore inherit their inability to distribute over nonatomic domains, no matter if these domains are mass or temporal.

There are multiple ways in which one could extend the framework in this paper and in Champollion 2016a. Cao Yu (p.c.) brought my attention to sentences with multiple distributors such as the one-on-one tutoring costs $\$ 100$ per person per hour. The semantics of per person could be given in essentially the same terms as one person each. One relevant advantage of the present framework in this connection is that the distributivity operators in Champollion 2016a are stackable: each of them has the same input and output type, namely $\langle v, t\rangle$. This is an advantage compared to Link's and Schwarzschild's original formulation of their distributivity operators, which is not stackable because it returns a truth value. Yenan Sun and Ziren Zhou (p.c.) suggest that the present account may be applicable to the Chinese nonatomic distributor dou (e.g., Lin 1998) and to the atomic distributor ge. Finally, the framework described here could be extended to each other and related reciprocals (LaTerza 2014a).

Taken together, this paper and its counterpart, Champollion 2016a, suggest the following general picture of distributivity. This general picture is itself part of a broader theoretical framework that also encompasses applications to aspect and measurement (Champollion 2010b, 2015c). No matter whether distributivity is introduced by an overt or by a covert element, it always involves a certain domain that contains the individuals or the material to be distributed over, and a certain size or granularity that specifies how finely the relevant predicates are distributed. When the domain in question is a count domain, for example when we distribute over people or objects, then it is always possible to distribute over these objects one by one. When the domain in question does not make such atomic units available, as in the case of time or space, two things can happen. Either the element in question does 
not allow distribution over such nonatomic domains, for example because it is incompatible with noncount domains to begin with, or else it looks for a salient cover or set in the context, such as a salient set of temporal locations. Those distributive items that can do this in principle can also do this in count domains even though atoms are available.

\section{References}

Aldridge, Maurice Vincent. 1982. English quantifiers: A study of quantifying expressions in linguistic science and modern English usage. Avebury, UK: Avebury.

Balusu, Rahul. 2005. Distributive reduplication in Telugu. North East Linguistic Society (NELS) 36. 39-53. http://semanticsarchive.net/Archive/mEoYTZkZ.

Balusu, Rahul \& Karattuparambil A. Jayaseelan. 2013. Distributive quantification by reduplication in Dravidian. In Strategies of quantification, 6o-86. Oxford, UK: Oxford University Press. https://doi.org/10.1093/acprof: oso/9780199692439.003.0004.

Barker, Chris. 2002. Continuations and the nature of quantification. Natural Language Semantics 10(3). 211-242. https://doi.org/10.1023/a: 1022183511876.

Barwise, Jon \& Robin Cooper. 1981. Generalized quantifiers and natural language. Linguistics and Philosophy 4(2). 159-219. https://doi.org/10.1007/ bfoo350139.

Bayer, Samuel L. 1997. Confessions of a lapsed Neo-Davidsonian: Events and arguments in compositional semantics. New York, NY: Garland. https: //doi.org/10.4324/9780203055106.

Beghelli, Filippo. 1997. The syntax of distributivity and pair-list readings. In Anna Szabolcsi (ed.), Ways of scope taking, vol. 65 (Studies in Linguistics and Philosophy), chap. 10, 349-408. Dordrecht, Netherlands: Kluwer Academic. https://doi.org/10.1007/978-94-011-5814-5_10.

Beghelli, Filippo \& Tim Stowell. 1997. Distributivity and negation: The syntax of each and every. In Anna Szabolcsi (ed.), Ways of scope taking, vol. 65, 71-107. Dordrecht, Netherlands: Kluwer. https://doi.org/10.1007/978-94011-5814-5_3.

Bittner, Maria. 1994. Cross-linguistic semantics. Linguistics and Philosophy 17(1). 53-108. https://doi.org/10.1007/bfoog85041. 
Overt distributivity in algebraic event semantics

Blaheta, Don. 2003. Binominal each: Evidence for a modified type system. Providence, RI: Brown University MA thesis. http://citeseerx.ist.psu.edu/ viewdoc/summary?doi=10.1.1.10.7455.

Bobaljik, Jonathan D. 1995. Morphosyntax: The syntax of verbal inflection. Cambridge, MA: Massachusetts Institute of Technology dissertation. http: //www.ai.mit.edu/projects/dm/theses/bobaljik95.pdf.

Bobaljik, Jonathan D. 2001. Floating quantifiers: Handle with care. In Lisa Cheng \& Rint Sybesma (eds.), The second state-of-the-article book (45-68). Berlin, Germany: de Gruyter. https://doi.org/10.1515/9783110890952.107. Bortolussi, Bernard. 2013. Latin quisque as a "floating" quantifier. Journal of Latin Linguistics 12(1). 5-26. https://doi.org/10.1515/joll-2013-0002.

Brasoveanu, Adrian \& Jakub Dotlačil. 2015. Strategies for scope taking. Natural Language Semantics 23(1). 1-19. https://doi.org/10.1007/s11050-0149109-1.

Brasoveanu, Adrian \& Donka F. Farkas. 2011. How indefinites choose their scope. Linguistics and Philosophy 34(1). 1-55. https://doi.org/10.1007/ s10988-011-9092-7.

Büring, Daniel. 2005. Binding theory. Cambridge, UK: Cambridge University Press. https://doi.org/10.1017/cbo9780511802669.

Burzio, Luigi. 1986. Italian syntax: A government-binding approach. Berlin, Germany: Springer. https://doi.org/10.1007/978-94-009-4522-7.

Cable, Seth. 2014. Distributive numerals and distance distributivity in Tlingit (and beyond). Language 9o(3). 562-6o6. https://doi.org/10.1353/lan.2014. 0055 .

Champollion, Lucas. to appear. Distributivity, collectivity and cumulativity. In Lisa Matthewson, Cécile Meier, Hotze Rullmann \& Thomas Ede Zimmermann (eds.), Wiley's companion to semantics. Hoboken, NJ: Wiley. http://ling.auf.net/lingbuzz/oo2133.

Champollion, Lucas. 2010a. Cumulative readings of every do not provide evidence for events and thematic roles. Logic, Language and Meaning: 17th Amsterdam Colloquium. 213-222. https://doi.org/10.1007/978-3-64214287-1_22.

Champollion, Lucas. 2010b. Parts of a whole: Distributivity as a bridge between aspect and measurement. Philadelphia, PA: University of Pennsylvania dissertation. http://repository.upenn.edu/edissertations/958/.

Champollion, Lucas. 2012. Each vs. jeweils: A cover-based view on distance distributivity. Logic, Language and Meaning: 18th Amsterdam Colloquium. 251-26o. https://doi.org/10.1007/978-3-642-31482-7_26. 
Champollion, Lucas. 2013. The scope and processing of for-adverbials: A reply to Deo and Piñango. Semantics and Linguistic Theory (SALT) 23. 432-452. https://doi.org/10.3765/salt.v23io.2680.

Champollion, Lucas. 2015a. Every boy bought two sausages each: Distributivity and dependent numerals. West Coast Conference on Formal Linguistics (WCCFL) 32. 103-110. http://www.lingref.com/cpp/wccfl/32/abstract3161. html.

Champollion, Lucas. 2015b. Refining stratified reference. Theoretical Linguistics 41(3-4). 223-240. https://doi.org/10.1515/tl-2015-0015.

Champollion, Lucas. 2015c. Stratified reference: The common core of distributivity, aspect, and measurement. Theoretical Linguistics 41(3-4). 109-149. https://doi.org/10.1515/tl-2015-00o8.

Champollion, Lucas. 2015d. The interaction of compositional semantics and event semantics. Linguistics and Philosophy 38(1). 31-66. https://doi.org/ 10.1007/s10988-014-9162-8.

Champollion, Lucas. 2016a. Covert distributivity in algebraic event semantics. Semantics and Pragmatics 9(15). 1-65. https://doi.org/10.3765/sp.9.15.

Champollion, Lucas. 2016b. Ten men and women got married today: Noun coordination and the intersective theory of conjunction. Journal of Semantics 33(3). 561-622. https://doi.org/10.1093/jos/ffvoo8.

Champollion, Lucas. 2017. Parts of a whole: Distributivity as a bridge between aspect and measurement. 1st edn. Vol. 66 (Oxford Studies in Theoretical Linguistics). Oxford, UK: Oxford University Press. https://doi.org/10. 1093/oso/9780198755128.001.0001.

Champollion, Lucas \& Manfred Krifka. 2016. Mereology. In Maria Aloni \& Paul Dekker (eds.), Cambridge handbook of formal semantics (Cambridge Handbooks in Language and Linguistics), chap. 13, 369-388. Cambridge, UK: Cambridge University Press. https://doi.org/10.1017/CBO9781139236157. O14.

Choe, Jae-Woong. 1987. Anti-quantifiers and a theory of distributivity. Amherst, MA: University of Massachusetts dissertation. http://scholarworks. umass.edu/dissertations/AAI8727027.

Chomsky, Noam. 1981. Lectures on government and binding. Dordrecht, Netherlands: Foris. https://doi.org/10.1515/9783110884166.

Collins, Chris \& Paul Martin Postal. 2012. Imposters: A study of pronominal agreement. MIT Press. https://doi.org/10.7551/mitpress/9780262016889. o01.0001. 
Overt distributivity in algebraic event semantics

Doetjes, Jenny. 1997. Quantifiers and selection: On the distribution of quantifying expressions in French, Dutch and English. The Hague, Netherlands: Holland Institute of Generative Linguistics dissertation. http://hdl.handle. net/1887/19731.

Dotlačil, Jakub. 2011. Fastidious distributivity. Semantics and Linguistic Theory (SALT) 21. 313-332. https://doi.org/10.3765/salt.v21io.2596.

Dotlačil, Jakub. 2012. Binominal each as an anaphoric determiner: Compositional analysis. In Ana Aguilar Guevara, Anna Chernilovskaya \& Rick Nouwen (eds.), Sinn und Bedeutung 16, 211-224. Cambridge, MA: MIT Working Papers in Linguistics. http://mitwpl.mit.edu/open/sub16/Dotlacil.pdf.

Dotlačil, Jakub. 2013. Reciprocals distribute over information states. Journal of Semantics 30(4). 423-477. https://doi.org/10.1093/jos/ffso16.

Dowty, David R. \& Belinda Brodie. 1984. The semantics of "floated" quantifiers in a transformationless grammar. West Coast Conference on Formal Linguistics (WCCFL) 3. 75-90.

Farkas, Donka F. 1997. Dependent indefinites. In Francis Corblin, Danièle Godard \& Jean-Marie Marandin (eds.), Empirical issues in formal syntax and semantics, 243-268. Bern, Switzerland: Peter Lang. http://people.ucsc. edu/ farkas/papers/reduplication.pdf.

Ferreira, Marcelo. 2005. Event quantification and plurality. Cambridge, MA: Massachusetts Institute of Technology dissertation. http://hdl.handle. net/1721.1/33697.

Gil, David. 1982. Distributive numerals. Los Angeles, CA: University of California dissertation.

Gil, David. 1993. Nominal and verbal quantification. STUF - Language Typology and Universals 46(1-4). https://doi.org/10.1524/stuf.1993.46.14.275.

Gil, David. 1995. Universal quantifiers and distributivity. In Emmon Bach, Eloise Jelinek, Angelika Kratzer \& Barbara Hall Partee (eds.), Quantification in natural languages, vol. 54 (Studies in Linguistics and Philosophy), 321362. Dordrecht, Netherlands: Kluwer. https://doi.org/10.1007/978-94017-2817-1_11.

Gil, David. 2013. Distributive numerals. In Matthew S. Dryer \& Martin Haspelmath (eds.), The world atlas of language structures online. Leipzig, Germany: Max Planck Institute for Evolutionary Anthropology. http://wals. info/chapter/54.

Gillon, Brendan S. 1987. The readings of plural noun phrases in English. Linguistics and Philosophy 10(2). 199-219. https://doi.org/10.1007/ bfoo584318. 
Gillon, Brendan S. 1990. Plural noun phrases and their readings: A reply to Lasersohn. Linguistics and Philosophy 13(4). 477-485. https://doi.org/10. 1007/bfoo630751.

Grevisse, Maurice. 1980. Le bon usage: Grammaire française, avec des remarques sur la langue française d'aujourd'hui. Paris, France: Duculot.

Heim, Irene, Howard Lasnik \& Robert May. 1991. Reciprocity and plurality. Linguistic Inquiry 22(1). 63-101. http://www.jstor.org/stable/4178708.

Hendriks, Herman. 1993. Studied flexibility. Amsterdam, Netherlands: University of Amsterdam dissertation.

Hogg, Richard M. 1977. English quantifier systems. North Holland.

Iordăchioaia, Gianina \& Elena Soare. 2015. Pluractionality with lexically cumulative verbs. Natural Language Semantics 23(4). 307-352. https://doi.org/ 10.1007/s11050-015-9117-9.

Ioup, Georgette. 1975. Some universals for quantifier scope. Syntax and Semantics $4 \cdot 37-58$.

Jackendoff, Ray S. 1972. Semantic interpretation in generative grammar. Cambridge, MA: MIT Press.

Janke, Vikki \& Ad Neeleman. 2012. Ascending and descending VPs in English. Linguistic Inquiry 43(2). 151-19o. https://doi.org/10.1162/ling_a_ooo82.

Junker, Marie-Odile. 1995. Syntaxe et sémantique des quantifieurs flottants tous et chacun: Distributivité en sémantique conceptuelle. Vol. 28. Geneva, Switzerland: Librairie Droz.

Keim, Marybelle C. \& John P. Murray. 2008. Chief academic officers' demographics and educational backgrounds. Community College Review 36(2). 116-132. https://doi.org/10.1177/oog1552108324657.

Kratzer, Angelika. 2000. The event argument and the semantics of verbs, chapter 2. Ms. University of Massachusetts, Amherst. http://semanticsarchive.net/Archive/GU1NWM4Z/.

Kratzer, Angelika. 2007. On the plurality of verbs. In Johannes Dölling, Tatjana Heyde-Zybatow \& Martin Schäfer (eds.), Event structures in linguistic form and interpretation, 269-30o. Berlin, Germany: de Gruyter. https://doi.org/ 10.1515/9783110925449.269.

Kroch, Anthony S. 1974. The semantics of scope in English. Cambridge, MA: Massachusetts Institute of Technology dissertation. http://hdl.handle. net/1721.1/13020.

Kuhn, Jeremy. 2015. Cross-categorial singular and plural reference in sign language. New York University dissertation. http://www.jeremykuhn.net/ papers/Kuhn-dissertation.pdf. 
Overt distributivity in algebraic event semantics

Landman, Fred. 1989. Groups, I. Linguistics and Philosophy 12(5). 559-605. https://doi.org/10.1007/bfoo627774.

Landman, Fred. 2004. Indefinites and the type of sets. Oxford, UK: Blackwell Publishing. https://doi.org/10.1002/9780470759318.

Lasersohn, Peter. 1989. On the readings of plural noun phrases. Linguistic Inquiry 20(1). 130-134. http://www.jstor.org/stable/4178619.

Lasersohn, Peter. 1995. Plurality, conjunction and events. Dordrecht, Netherlands: Kluwer. https://doi.org/10.1007/978-94-015-8581-1.

Lasersohn, Peter. 1998. Generalized distributivity operators. Linguistics and Philosophy 21(1). 83-93. https://doi.org/10.1023/a:1005317815339.

LaTerza, Chris. 2014a. Distributivity and plural anaphora. College Park, MD: University of Maryland dissertation. http://hdl.handle.net/1903/15826.

LaTerza, Chris. 2014b. Local plural anaphora as sub-event distributivity. West Coast Conference on Formal Linguistics (WCCFL) 32. 141-148. http: //www.lingref.com/cpp/wccfl/32/paper3165.pdf.

Lin, Jo-Wang. 1998. Distributivity in Chinese and its implications. Natural Language Semantics 6(2). 201-243. https://doi.org/10.1023/a:1008299031574.

Link, Godehard. 1987. Generalized quantifiers and plurals. In Peter Gärdenfors (ed.), Generalized quantifiers, 151-180. Reprinted in Link 1998a, Chapter 4. Berlin, Germany: Springer. https://doi.org/10.1007/978-94-oo9-3381-1_6.

Link, Godehard. 1998a. Algebraic semantics in language and philosophy. Stanford, CA: CSLI Publications.

Link, Godehard. 1998b. Je drei äpfel-three apples each: Quantification and the German 'je'. In Godehard Link (ed.), Algebraic semantics in language and philosophy, 117-132. Stanford, CA: CSLI Publications.

Maling, Joan M. 1976. Notes on quantifier-postposing. Linguistic Inquiry 7(4). 708-718. http://www.jstor.org/stable/4177962.

Moltmann, Friederike. 1992. Reciprocals and same/different: Towards a semantic analysis. Linguistics and Philosophy 15(4). 411-462. https://doi. org/10.1007/bfoo627683.

Moltmann, Friederike. 1997. Parts and wholes in semantics. Oxford, UK: Oxford University Press.

Montague, Richard. 1973. The proper treatment of quantification in ordinary English. In Jaakko Hintikka, Julius Moravcsik \& Patrick Suppes (eds.), Approaches to natural language: 1970 Stanford workshop on grammar and semantics, 221-242. Dordrecht, Netherlands: Springer. https://doi. org/10.1007/978-94-010-2506-5_10. 
Müller, Ana \& Esmeralda Negrão. 2012. On distributivity in Karitiana. In Patricia Cabredo Hofherr \& Brenda Laca (eds.), Verbal plurality and distributivity, vol. 546 (Linguistische Arbeiten), 159-184. de Gruyter. https: //doi.org/10.1515/9783110293500.159.

Oh, Sei-Rang. 2001. Distributivity in an event semantics. Semantics and Linguistic Theory (SALT) 11. 326-345. https://doi.org/10.3765/salt.v11io.2844.

Oh, Sei-Rang. 2006. Plurality markers across languages. Storrs, CT: University of Connecticut dissertation. http://digitalcommons.uconn.edu / dissertations/AAI3236140.

Petrova, Milena. 2000. The distributive marker po in Bulgarian. Ms. University of Southern California.

Piñón, Christopher. 2000. Distributive po- in Polish. Presentation at Sinn und Bedeutung V, Amsterdam. http://pinon.sdfeu.org/work/pinon_dpp_ho_ 200o.pdf.

Postal, Paul Martin. 1974. On raising. Cambridge, MA: MIT Press.

Przepiórkowski, Adam. 2013. The syntax of distance distributivity in Polish: Preserving generalisations with weak heads. In Stefan Müller (ed.), Head-driven Phrase Structure Grammar (HPSG) 2013 conference, freie universität berlin, 161-181. Stanford, CA: CSLI Publications. https://web. stanford.edu/group/cslipublications/cslipublications/HPSG/2013/abstrprzepiorkowski.shtml.

Przepiórkowski, Adam. 2014a. Distance distributivity in Polish: Towards a Glue Semantics approach. In Christopher Piñón (ed.), Empirical issues in syntax and semantics 10: Colloque de Syntaxe et Sémantique à Paris (CSSP) 2013, 107-124. http://www.cssp.cnrs.fr/eiss1o/.

Przepiórkowski, Adam. 2014b. Syntactic and semantic constraints in a Glue Semantics approach to distance distributivity. Lexical Functional Grammar (LFG) '14. 482-502. http://cslipublications.stanford.edu/LFG/19/lfg14. html.

Przepiórkowski, Adam. 2015. A weakly compositional analysis of distance distributivity in Polish. In Małgorzata Szajbel-Keck, Roslyn Burns \& Darya Kavitskaya (eds.), Formal Approaches to Slavic Linguistics (FASL) 23, 262281. Ann Arbor, MI. http://nlp.ipipan.waw.pl/Bib/prze:14:fasl.pdf.

Pylkkänen, Liina. 2008a. Introducing arguments. Cambridge, MA: MIT Press. https://doi.org/10.7551/mitpress/9780262162548.001.0001.

Pylkkänen, Liina. 2008b. Mismatching meanings in brain and behavior. Language and Linguistics Compass 2(4). 712-738. https://doi.org/10.1111/j. 1749-818x.2008.00073.X. 
Overt distributivity in algebraic event semantics

Roberts, Craige. 1987. Modal subordination, anaphora, and distributivity. Amherst, MA: University of Massachusetts dissertation. http://scholarworks. umass.edu/dissertations/AAI8710499.

Rothstein, Susan. 1995. Adverbial quantification over events. Natural Language Semantics 3(1). 1-31. https://doi.org/10.1007/bfo1252883.

Rothstein, Susan. 2010. Counting and the mass/count distinction. Journal of Semantics 27(3). 343-397. https://doi.org/10.1093/jos/ffqoo7.

Safir, Ken \& Tim Stowell. 1988. Binominal each. North East Linguistic Society (NELS) 18. 426-450. http://www.linguistics.ucla.edu/people/stowell/SafirStowell_-_Binominal_Each_-_NELS_1988_ocr.pdf.

Sakaguchi, Mari. 1998. Distributivity in English and Japanese. Los Angeles, CA: University of California dissertation.

Schein, Barry. 1993. Plurals and events. Cambridge, MA: MIT Press.

Schwarz, Florian. 2009. Two types of definites in natural language. Amherst, MA: University of Massachusetts dissertation. http://scholarworks.umass. edu/open_access_dissertations/122.

Schwarzschild, Roger. 1996. Pluralities. Vol. 61 (Studies in Linguistics and Philosophy). Dordrecht, Netherlands: Kluwer. https://doi.org/10.1007/ 978-94-017-2704-4.

Schwarzschild, Roger. 2014. Distributivity, negation and quantification in event semantics: Recent work by L. Champollion. Ms. Massachusetts Institute of Technology. http://web.mit.edu/schild/www/papers/public_ html/champ.pdf.

Spevak, Olga. 2014. The noun phrase in classical Latin prose (Amsterdam Studies in Classical Philology). Brill. https://doi.org/10.1163/9789004265684.

Sportiche, Dominique. 1988. A theory of floating quantifiers and its corollaries for constituent structure. Linguistic Inquiry 19(3). 425-449. http://www. jstor.org/stable/25164903.

Stanley, Jason \& Zoltán Gendler Szabó. 2000. On quantifier domain restriction. Mind and Language 15(2-3). 219-261. https:// doi.org/10.1111/1468o017.00130.

Sutton, Melody. 1993. Binominal “each”. Los Angeles, CA: University of California MA thesis.

Szabolcsi, Anna. 2010. Quantification. Cambridge, UK: Cambridge University Press. https://doi.org/10.1017/cbo9780511781681.

Tasmowski-De Ryck, Liliane \& S. Paul Verluyten. 1982. Linguistic control of pronouns. Journal of Semantics 1(4). 323-346. https://doi.org/10.1093/ jos/1.3-4.323. 
Taylor, Barry. 1985. Modes of occurrence. Oxford, UK: Basil Blackwell.

Tellier, Christine \& Daniel Valois. 1993. Binominal chacun and pseudo-opacity. Linguistic Inquiry 24(3). 575-583. http://www.jstor.org/stable/4178830.

Thomas, Guillaume. 2015. The present tense is not vacuous. Journal of Semantics 32(4). 685-747. https://doi.org/10.1093/jos/ffuo10.

Thomas, Guillaume \& Yasutada Sudo. 2016. Cumulative readings of each. Presentation at the Workshop on (Co-)Distributivity, Paris, February 11-12, 2016. https://www.ucl.ac.uk/ ucjtudo/pdf/eachParis2016.pdf.

Tunstall, Susanne Lynn. 1998. The interpretation of quantifiers: Semantics \& processing. Amherst, MA: University of Massachusetts dissertation.

Vendler, Zeno. 1967. Linguistics in philosophy. Ithaca, NY: Cornell University Press.

Williams, Alexander. 2009. Themes, cumulativity, and resultatives: Comments on Kratzer 2003. Linguistic Inquiry 40(4). 686-700. https://doi.org/10. 1162/ling.2009.40.4.686.

Williams, Edwin. 1991. Reciprocal scope. Linguistic Inquiry 22(1). 159-173. http://www.jstor.org/stable/4178711.

Winter, Yoad. 2001. Flexibility principles in Boolean semantics: The interpretation of coordination, plurality, and scope in natural language. Cambridge, MA: MIT Press.

Zimmermann, Malte. 2002a. A compositional analysis of anti-quantifiers as quantifiers. Semantics and Linguistic Theory (SALT) 12. 322-338. https: //doi.org/10.3765/salt.v12io.2876.

Zimmermann, Malte. 2002b. Boys buying two sausages each: On the syntax and semantics of distance-distributivity. Amsterdam, Netherlands: University of Amsterdam dissertation. http://hdl.handle.net/11245/1.194584.

Zimmermann, Malte. 2008. Quantification in Hausa. In Lisa Matthewson (ed.), Quantification: Universals and variation, vol. 64 (North Holland Linguistic Series: Linguistic Variations), chap. 11, 415-475. Bingley, UK: Emerald.

Zucchi, Sandro \& Michael White. 2001. Twigs, sequences and the temporal constitution of predicates. Linguistics and Philosophy 24(2). 223-270. https: //doi.org/10.1023/a:1005690022190.

Zweig, Eytan. 2008. Dependent plurals and plural meaning. New York, NY: New York University dissertation. http://semanticsarchive.net/Archive/ GJhMzhhZ/. 
Overt distributivity in algebraic event semantics

Lucas Champollion

New York University

10 Washington Place

New York, NY 10003, USA

champollion@nyu.edu 